University of Michigan Law School

University of Michigan Law School Scholarship Repository

\title{
Feigned Consensus: Usurping the Law in Shaken Baby Syndrome/ Abusive Head Trauma Prosecutions
}

\author{
Keith A. Findley \\ University of Wisconsin Law School \\ D. Michael Risinger \\ Seton Hall University School of Law \\ Patrick D. Barnes \\ Stanford University Medical Center \\ Julie A. Mack \\ Pennsylvania State University Medical Center \\ David A. Moran \\ University of Michigan Law School, morand@umich.edu
}

See next page for additional authors

Available at: https://repository.law.umich.edu/articles/2102

Follow this and additional works at: https://repository.law.umich.edu/articles

Part of the Criminal Procedure Commons, Evidence Commons, Juvenile Law Commons, and the Medical Jurisprudence Commons

\section{Recommended Citation}

Findley, Keith A. "Feigned Consensus: Usurping the Law in Shaken Baby Syndrome/Abusive Head Trauma Prosecutions." Michael Risinger, Patrick Barnes, Julie Mack, David A. Moran, Barry Scheck, and Thomas Bohan, co-authors. Wis. L. Rev. 2019, no. 4 (2019): 1211-268.

This Article is brought to you for free and open access by the Faculty Scholarship at University of Michigan Law School Scholarship Repository. It has been accepted for inclusion in Articles by an authorized administrator of University of Michigan Law School Scholarship Repository. For more information, please contact mlaw.repository@umich.edu. 


\section{Authors}

Keith A. Findley, D. Michael Risinger, Patrick D. Barnes, Julie A. Mack, David A. Moran, Barry C. Scheck, and Thomas L. Bohan 


\title{
FEIGNED CONSENSUS: \\ USURPING THE LAW IN SHAKEN BABY SYNDROME/ ABUSIVE HEAD TRAUMA PROSECUTIONS
}

\author{
KeITH A. Findley, $*$ D. Michael Risinger, $* *$ PATRICK D. \\ BARNES, $* * *$ JULIE A. MACK, $* * * *$ DAVID A. MORAN, $* * * * *$ BARRY C. \\ SCHECK, $* * * * * *$ \\ AND THOMAS L. BOHAN*******
}

\begin{abstract}
Few medico-legal matters have generated as much controversy-both in the medical literature and in the courtroom-as Shaken Baby Syndrome (SBS), now known more broadly as Abusive Head Trauma (AHT). The controversies are of enormous significance in the law because child abuse pediatricians claim, on the basis of a few non-specific medical findings supported by a weak and methodologically flawed research base, to be able to "diagnose" child abuse, and thereby to provide all of the evidence necessary to satisfy all of the legal elements for criminal prosecution (or removal of children from their parents). It is a matter, therefore, in which medical opinion claims to fully occupy the legal field. As controversies flare up increasingly in the legal arena, child abuse pediatricians and prosecutors now respond by claiming both that there is actually no real controversy about SBS/AHT, and that it is a purely medical "diagnosis" and not a legal conclusion, so testimony in support of the SBS hypothesis should not be challenged in court. This article, coauthored by four law professors, two physicians, and a physicist, demonstrates that there is very much a live controversy about the SBS/AHT hypothesis and maintains that, under traditional principles of evidence law, physicians should not be permitted to "diagnose" abuse in court (as opposed to identifying specific symptoms or medical findings).
\end{abstract}

Introduction

* Associate Professor of Law, University of Wisconsin Law School; Co-Founder and President, Center on Integrity in Forensic Science; Co-Founder, Wisconsin Innocence Project.

** John J. Gibbons Professor of Law Emeritus, Seton Hall University School of Law; Associate Director, Last Resort Exoneration Project.

*** M.D., Professor of Radiology, Emeritus-Pediatric Radiology \& Neuroradiology, Lucile Packard Children's Hospital at Stanford, Stanford University Medical Center.

**** M.D., Assistant Professor of Radiology, Pennsylvania State University Medical Center.

***** Clinical Professor of Law, University of Michigan Law School; CoFounder and Director, Michigan Innocence Clinic.

****** Professor of Law, Cardozo Law School; Co-Founder \& Co-Director, Innocence Project.

******* Ph.D. (physics), Past President, American Academy of Forensic Sciences (2009-2010); Past President, Forensic Specialties Accreditation Board (201517); Director (retired), MTC Forensics (1982-2013). 
I. Is SBS/AHT Controversial?................................ 1216

A. Controversy in the Medical Literature ................. 1217

B. Controversy in the Biomechanical and Scientific

Literature........................................ 1220

C. Uncertainty about SBS Mechanisms and Conclusions .... 1222

D. Controversy in the Face of Claimed Consensus .......... 1225

E. Broad Claims, Nuanced Controversies ................ 1231

F. Recognizing Controversy: Independent Scientific

Reviews ....................................... 1232

G. Judicial Recognitions of the Shifting Science and

Attendant Controversy ............................... 1234

II. Is AHT a "Medical Diagnosis" or a "Legal Conclusion"?...... 1236

A. The SPR's Claims ..................................... 1236

B. Foundational Question-Is the Conclusion of SBS/AHT

Even a "Diagnosis" as that Term is Used in Medicine? 1238

C. The Legal Essence of the "Diagnosis" .................. 1246

III. Implications of the Controversies and Legal Nature of the

SBS/AHT Conclusions .................................. 1254

A. The Significance of the Legal Nature of the SBS/AHT

Conclusion ......................................... 1254

1. The Limitations of Medical Expertise in a Legal

Context ........................................ 1254

2. Admissibility Issues Arising from the Legal Nature of the "Diagnosis" ................................ 1258

B. Legal Implications of the Controversy ................. 1261

Conclusion............................................... 1262

\section{INTRODUCTION}

Few medico-legal matters have generated as much controversyboth in the medical literature and in the courtroom-as Shaken Baby Syndrome (SBS), now known more broadly, at the urging of the American Academy of Pediatrics, as Abusive Head Trauma (AHT). ${ }^{1}$ The medical and legal literature is replete with research and opinion pieces debating all aspects of the hypothesis $;{ }^{2}$ entire sessions at medical and legal conferences are devoted to examining the disputed issues and

1. Cindy W. Christian, Robert Block, \& the Committee on Child Abuse and Neglect, Abusive Head Trauma in Infants and Children, 123 Pediatrics 1409, 1410 (2009) ("[T]he American Academy of Pediatrics recommends adoption of the term 'abusive head trauma' as the diagnosis used in the medical chart to describe the constellation of cerebral, spinal, and cranial injuries that result from inflicted head injury to infants and young children.").

2. See infra notes 22-29 and accompanying text. 
strategizing ways to defeat the other side in these debates; ${ }^{3}$ and growing numbers of courts are recognizing the controversies and overturning convictions on the basis of the expanding uncertainties related to medical opinion purporting to diagnose abuse. ${ }^{4}$

3. See, e.g., Keith A. Findley et al., Shaken Baby Syndrome, Abusive Head Trauma, and Actual Innocence: Getting It Right, 12 Hous. J. HeAlth L. \& Pol'y 209, 241 (2012) (observing that the National Association of Medical Examiners conference in 2006 "included presentations entitled 'Use of the Triad of Scant Subdural Hemorrhage, Brain Swelling, and Retinal Hemorrhages to Diagnose Non-Accidental Injury is Not Scientifically Valid' and “"Where's the Shaking?"' Dragons, Elves, the Shaking Baby Syndrome and Other Mythical Entities."”); Robert M. Reece et al., The Evidence Base for Shaken Baby Syndrome: Response to Editorial from 106 Doctors, 328 Brit. MED. J. 1316, 1316-17 (2004); Brian Holmgren, Assistant District Attorney General, Keynote Address at Eleventh International Conference on Shaken Baby Syndrome/Abusive Head Trauma: To Tell the Truth - Examining Defense Witness Testimony in Abusive Head Trauma Cases (Sept. 13, 2010), https://www.dontshake.org/media/k2/attachments/2010-AtlantaProgram.pdf [https://perma.cc/YDQ7-96CC] (presentation notes and lyrics on file with authors).

4. See, e.g., People v. Ackley, 870 N.W.2d 858 (Mich. 2015) (finding ineffective assistance of counsel for failure to present medical evidence disputing the prosecution experts' SBS/AHT-based opinions); People v. Bailey, 999 N.Y.S.2d 713, 724 (N.Y.S. Cnty. Ct. 2014) (finding newly discovered evidence of emerging medical research challenging the SBS/AHT diagnosis); People v. Baumer, No. 267373, 2007 WL 1095236, at $* 1$, *4 (Mich. Ct. App. Apr. 12, 2007) (discussing ineffective assistance of counsel), motion for immediate consideration granted, 781 N.W.2d 309 (Mich. 2010); Ex Parte Briggs, 187 S.W.3d 458, 469-70 (Tex. Crim. App. 2005) (finding ineffective assistance of counsel); Armando Castillo: Actual Innocence - Invalid Science Conviction Vacated, AZ Just. Project (May 21, 2015), https://

www.azjusticeproject.org/manifest-injustice-profiles/armando-castillo [https://perma.cc/9VH9-HYH9] (discussing the judge's conclusion of ineffective assistance of counsel and newly discovered evidence); Brafford v. State, No. PC-2014-803 (Okla. Crim. App. March 26, 2019) (finding ineffective assistance of counsel and newly discovered evidence warranted new trial); Brown v. State, 152 So.3d 1146, 1169 (Miss. 2014) (concluding that the trial court erroneously denied funds for defense to hire experts to challenge state's expert medical evidence); People v. Dimambro, 897 N.W.2d 233 (Mich. Ct. App. 2016); Barry Siegel, Judging Parents as Murderers on 4 Specks of
Blood, L.A.
TIMES
(July
11 ,
1999), http://

articles.latimes.com/1999/jul/11/news/mn-54984 [https://perma.cc/5WCV-J9LK] (discussing newly discovered evidence); Commonwealth v. Epps, 53 N.E.3d 1247, 1266 (Mass. 2016) (discussing ineffective assistance of counsel and newly discovered evidence); In re Pers. Restraint of Fero, 367 P.3d 588, 600 (Wash. Ct. App. 2016) (discussing newly discovered medical evidence), rev'd, 409 P.3d 214, 226 (Wash. 2018); State v. Hales, 152 P.3d 321, 325 (Utah 2007) (finding ineffective assistance of counsel); Ex Parte

Henderson, 384 S.W.3d 833, 834 (Tex. Crim. App. 2012) (noting the effect of newly discovered medical evidence); Order on Defendant's Motion to Disallow the Introduction of Testimony Regarding Shaken Baby Syndrome, State v. Hyatt, No. 06M7-CR00016-02 (Cir. Ct. Shelby Cty. Nov. 2007) (discussing newly discovered medical evidence); Isham v. State, 161 So.3d 1076, 1077 (Miss. 2015) (holding that the defendant was entitled to a publicly funded expert to refute the prosecution's SBS/AHT scientific evidence); Maurice Possley, Joel Lehmer, NAT'L REgISTRY OF EXONERATIONS (July 29, 2012), https://www.law.umich.edu/special/exoneration/ Pages/casedetail.aspx? caseid $=3953$

[https://perma.cc/8FE4-DQT9] (concluding that newly discovered medical evidence 
Increasingly, proponents of the SBS/AHT "diagnosis" have attempted to take the debate away from the courts through efforts to delegitimize those who criticize or challenge some aspects of the SBS/AHT hypothesis. Instead of encouraging full airing of scientific debate-a hallmark of true scientific inquiry-SBS/AHT-hypothesis proponents have sought to silence debate and dissent by demeaning physicians who break ranks, ${ }^{5}$ attempting to strip the critics of their medical licenses and society memberships ${ }^{6}$ or jobs, ${ }^{7}$ attempting to bar

warranted vacating the convictions); Joseph Shapiro, Free, but Not Cleared: Ernie Lopez Comes Home, NPR (Mar. 5, 2012, 4:06 PM), https://www.npr.org/2012/03/05/147969316/free-but-not-cleared-ernie-lopez-comeshome [https://perma.cc/NM2H-SBWY] (discussing ineffective assistance of counsel and newly discovered medical evidence); Kenneth Marsh, CALIFORNIA InNOCENCE PROJECT, https://californiainnocenceproject.org/read-their-stories/kenneth-marsh/ [https://perma.cc/754S-6HAL] (discussing the dismissal of charges in light of newly discovered evidence); Commonwealth v. Millien, 50 N.E.3d 808, 809 (Mass. 2016) (concluding ineffective assistance of counsel); Alexandra Gross, John Peel, NAT'L REGISTRY $\mathrm{OF}$ EXONERATIONS, https://www.law.umich.edu/special/exoneration/Pages/casedetail.aspx? caseid $=3813$ [https://perma.cc/VSV8-3XX3] (reversing defendant's convictions in light of newly discovered evidence); State v. Schoonmaker, 176 P.3d 1105, 1108 (N.M. 2008) (reversing defendant's convictions on the basis of ineffective assistance of counsel); State v. Weaver, 554 N.W.2d 240, 250 (Iowa 1996) (holding that the lower court did not unreasonably conclude that newly discovered evidence probably would change the result at trial). Still other courts have also granted relief under the more difficult standards requiring a petitioner to establish actual innocence. See, e.g., Del Prete v. Thompson, 10 F. Supp. 3d 907, 909 (N.D. Ill. 2014) (holding that medical evidence challenging the state's SBS/AHT-based opinions established the petitioner's "actual innocence" sufficiently to permit her to proceed on otherwise defaulted claims); Robins v. State, 385 P.3d 57 (Nev. 2016) (holding that, in part, new medical evidence established defendant's actual innocence claim, permitting defendant to proceed on otherwise defaulted claims).

5. See Findley et al., supra note 3, at 226-27 and notes 54-55 (describing how Dr. Christopher Greeley, Assoc. Professor of Pediatrics, Univ. of Tex. Health Sci. Ctr. at Houston, while presenting at New York City Abusive Head Trauma/Shaken Baby Syndrome Training Conference in 2011, suggested that researchers who question SBS/AHT theory use "sleaze tactics" and may have "histrionic/borderline" personality disorders; also noting that high-profile SBS/AHT prosecutor Brian Holmgren, who presented the Keynote Address at the Eleventh International Conference on Shaken Baby Syndrome/Abusive Head Trauma: To Tell the Truth-Examining Defense Witness Testimony in Abusive Head Trauma Cases, showed excerpts of testimony from defense experts juxtaposed with an image of Pinocchio with a growing nose, concluding with a sing-along to the tune of "If I only had a brain" led by a prominent child abuse pediatrician, joined by prosecutors and doctors, mocking those who propose diagnostic alternatives to SBS/AHT).

6. See, e.g., Peter J. Strouse, Child Abuse: We Have Problems, 46 PEDIATRIC RADIOLOGY 587, 588 (2016) (disparaging SBS/AHT "denialists" as "deceitful and unethical" and arguing that "[1]icensing bureaus could have a role by limiting practice" and that professional societies "should question condoning the activities of denialists by allowing them to continue membership and to continue to use society membership as evidence of expertise"). 
them from the courtroom, ${ }^{8}$ and even prosecuting them criminally for their expert testimony on behalf of criminal defendants. ${ }^{9}$

Recently, these efforts have taken the form of denying that there is any debate at all about the reliability of SBS and AHT-determinations. A recent very pointed example of that strategy, published as a so-called "consensus" statement by the Society for Pediatric Radiology (SPR), ${ }^{10}$ prompts us, as legal, medical, and science scholars, to respond.

While the particular article that motivates this response was published in a medical journal-Pediatric Radiology-we respond in a law journal because the SPR statement was written primarily for a legal audience-specifically, to influence judges in the way they handle conflicting expert opinions in SBS/AHT cases and to equip prosecutors to overcome defense challenges. Indeed, the statement directly addresses the legal system, with major section headings such as, "[t]he issues that perpetuate misconceptions in the courtroom," 11 and, "[w]hat can be done to provide the court accurate information about the state of medical knowledge in AHT," 12 along with subheadings such as, "[t]he admissibility of expert evidence," ${ }^{13}$ and the like. And the text speaks directly to the courts, asserting, for example, that "[c]ourts should assume that a consensus statement reflects general physician acceptance of a particular precept," ${ }^{14}$ and that, "[e]xperts, through consensus

7. See id. ("Institutions that harbor denialists, whether they be private practices or esteemed academic institutions, should carefully consider their employment.").

8. See, e.g., Doctor Wins Appeal Over Shaken Baby Syndrome Trials Evidence, THE GUARDIAN (Nov. 4, 2016), https://www.theguardian.com/society/2016/nov/04/doctor-waney-squier-wins-appealshaken-baby-syndrome-trials-evidence [https://perma.cc/WG5W-7VVZ] (describing efforts to revoke Dr. Waney Squier's medical license and ban her from testifying in child abuse cases); Mark Hansen, Battle of the Expert, A.B.A.J. (Dec. 29, 2005, 11:29 $\mathrm{AM}), \quad \mathrm{http} / / / \mathrm{www}$. abajournal.com/magazine/article/battle_of_the_expert [https://perma.cc/4CU3-9EG6] (describing a complaint filed with the Minnesota Board of Medical Practice in 1999 against Dr. John Plunkett after he testified on behalf of a baby sitter who was subsequently acquitted on charges of violently shaking a fourteenmonth-old boy; the complaint against Plunkett was ultimately dismissed).

9. See, e.g., Hansen, supra note 8 (describing perjury charges brought against Dr. John Plunkett in Oregon for his testimony in an SBS case-charges on which he was acquitted after a trial); Radley Balko, Dr. John Plunkett, RIP. He Told the Truth About Bad Forensics-and was Prosecuted for It, WASH. Post (Apr. 10, 2017, 1:13 PM), https://www.washingtonpost.com/news/the-watch/wp/2018/04/10/drjohn-plunkett-rip-he-told-the-truth-about-bad-forensics-and-was-prosecuted-forit/?utm term $=.99 \mathrm{c} 825 \mathrm{a} 28 \mathrm{f} 81$ (same).

10. Arabinda Kumar Choudhary et al., Consensus Statement on Abusive Head Trauma in Infants and Young Children, 48 Pediatric RADIOLOGY 1048 (2018).

11. Id. at 1057 .

12. Id. at 1058 .

13. Id.

14. Id. 
statements, can also help courts identify the medical evidence that reflects scientific knowledge because it is supported by the evidence and has been generally accepted in the relevant field of pediatric medicine." 15 This, the SPR asserts, will "assist courts in identifying testimonial parameters for expert testimony and help judges and juries delineate evidence-based medical knowledge from fringe, speculative, or professionally irresponsible opinions." 16 To sum it up, the statement concludes that " $[\mathrm{t}]$ he professional societies' consensus statement on AHT should help the court recognize unsubstantiated medical expert testimony." 17

Our response focuses on three points. First, we address the SPR's contention that there is in fact no dispute about SBS/AHT, and therefore no reason for courts and juries to be distracted by dissenting expert opinions. Second, we address the SPR's claim that SBS/AHT is purely a "medical diagnosis" and not at all a legal conclusion. Third, we address the clear implication in the SPR statement that, given the "general acceptance" purportedly represented by the consensus statement and the absolute absence of any real debate, the courts should defer entirely to the SPR and like-minded physicians' groups rather than making independent judicial inquiry into the reliability of proffered expert testimony. Under this last point, we address two implicit subpoints from the SPR statement: (1) that courts should accordingly admit prosecution-proffered testimony, but not defense-proffered contrary testimony, about SBS/AHT; and (2) that courts should stop drawing the legal conclusion that emerging controversies and shifts in medical understandings about SBS/AHT provide a basis for granting postconviction relief in cases where convictions were obtained without benefit of the now-growing body of contradictory medical and biomechanical science.

\section{IS SBS/AHT CONTROVERSIAL?}

In the debates about the reliability of the "diagnosis" of SBS/AHT, the recent tack by child abuse pediatricians is to deny that the debate exists-to deny there is any controversy at all. ${ }^{18}$ That approach is

\footnotetext{
15. Id.

16. Id.

17. Id. at 1060 .

18. Alternatively, child abuse pediatricians recognize the controversy but argue that it should be ignored because it can impede their ability to diagnose abuse. As Dr. Robert Block wrote in 1999: “Although controversy may spark scientific inquiry, it can interfere with proper recognition and management. When one cares for children who have been shaken, with or without impact, the controversy has no place in the diagnosis of abuse, which has obviously occurred in either case." Robert W. Block,
} 
apparent in the new SPR statement. The statement asserts, for example, that " $[t]$ here is no controversy concerning the medical validity of the existence of AHT, with multiple components including subdural hematoma, intracranial and spinal changes, complex retinal hemorrhages, and rib and other fractures that are inconsistent with the provided mechanism of trauma." 19 Later, the statement goes a step further, asserting, "AHT is a scientifically non-controversial medical diagnosis broadly recognized and managed throughout the world." ${ }^{20}$ According to the SPR, the purported controversy reflects merely false doubt generated by criminal defense attorneys and their unethical experts: "Efforts to create doubt about AHT include the deliberate mischaracterization and replacement of the complex and multifaceted diagnostic process by a near-mechanical determination based on the 'triad' - the findings of subdural hemorrhage, retinal hemorrhage and encephalopathy." 21

\section{A. Controversy in the Medical Literature}

This claim of non-controversy, however, stands in stark contrast to even a casual review of the literature, both medical and legal. Contrast, for example, the SPR's claim of no controversy to the following excerpt from the most recent official position paper of the American Academy of Pediatrics (AAP) (one of the most adamant proponents of the SBS/AHT hypothesis), published in 2009:

Few pediatric diagnoses engender as much debate as AHT, in part because of the social and legal consequences of the diagnosis. The diagnosis can result in children being removed from their homes, parents losing their parental rights, and adults being imprisoned for their actions. Controversy is fueled because the mechanisms and resultant injuries of accidental and abusive head injury overlap, the abuse is rarely witnessed, an accurate history of trauma is rarely offered by the perpetrator, there is no single or simple test to determine the accuracy of the diagnosis, and the legal consequences of the diagnosis can be so significant. ${ }^{22}$

Child Abuse-Controversies and Imposters, 29 CURRENT ProBs. Pediatrics 253, 255 (1999).

19. Choudhary, supra note 10 , at 1048 .

20. Id. at 1049 .

21. Id. at 1050 .

22. Christian, supra note 1 , at 1410 . Note the assumed conclusion that it the "perpetrator" who is giving the "history." 
Likewise, when the National Association of Medical Examiners initially adopted a position paper endorsing the SBS hypothesis in 2001-a paper it declined to renew when it expired five years later-the editor of the American Journal of Forensic Medicine and Pathology, which published the position paper, added a note to the published version of the paper explaining: "The manuscript was reviewed by three reviewers on the Board of Editors of the American Journal of Forensic Medicine and Pathology. They believed that while it was worthy of publication, it should not be published as a position paper because of the controversial nature of the subject." 23

The medical literature is replete with similar acknowledgements of the controversy. Many such statements are found in writings by SBS critics, as one would expect. ${ }^{24}$ But many acknowledgements are also found in articles by physicians who accept the basic premise of the hypothesis, ${ }^{25}$ and even by physicians who are the most vocal proponents

23. Mary E. Case et al., National Association of Medical Examiners, Ad Hoc Comm. on Shaken Baby Syndrome, Position Paper on Fatal Abusive Head Injuries in Infants and Young Children, 22 AM. J. ForensiC Med. Pathology 112, 112 (2001). The editor also noted: "The Board of Directors responded to this opinion by stating that position papers always deal with controversial subjects." Id.

24. See, e.g., Randy Papetti et al., Outside the Echo Chamber: A Response to the "Consensus Statement on Abusive Head Trauma in Infants and Young Children," 59 SANTA ClaRA L. REV. 299, 366 (2019) ("[SBS/AHT] is not merely controversial, but is perhaps the most controversial area in forensic medicine."); RANDY PAPETTI, THE Forensic Unreliability of the ShaKen Baby Syndrome 7 (Christopher Milroy ed. 2018) ("[T]oday such basic issues as what the 'syndrome' is and on what bases it is diagnosed are themselves hotly debated issues.”); Jacob Andersson \& Ingemar Thiblin, National Study Shows that Abusive Head Trauma Mortality in Sweden was at Least 10 Times Lower than in Other Western Countries, 107 ACTA PÆDIATRICA 477, 477 (2018) ("The validity of the diagnostic criteria for abusive head trauma (AHT) and its attributes has been widely debated."); Gören Höbgerb et al., Circularity Bias in Abusive Head Trauma Studies Could be Diminished with a New Ranking Scale, 6 EgYptian J. ForEnsic SCI. 6, 7 (2016) (“This hypothesis has been subjected to debate because the causal connection between exposure and clinical findings has never been established."); Steven C. Gabaeff, Exploring the Controversy in Child Abuse Pediatrics and False Accusations, 18 LEGAL MED. 90 (2016); JAN E. LEESTMA, ForensiC Neuropathology 642 (3d ed. 2014); Patrick D. Barnes, Ethical Issues in Imaging Nonaccidental Injury: Child Abuse, 13 Topics in Magnetic Resonance Imaging 85, 85 (2002) ("One of the most controversial areas of nonaccidental injury is the medical diagnosis of inflicted central nervous system injury and its impact on medical, social, and legal outcomes for children and families.").

25. See, e.g., Beth A. Costine-Bartell et al., Development of a Model of Hemispheric Hypodensity ("Big Black Brain”), 36 J. Neurotrauma 815, 816 (2019) ("[T]he exact etiological mechanisms that cause injury in children with AHT remain controversial . . . .”); Christopher J. Hobbs \& Robert A.C. Bilo, Nonaccidental Trauma: Clinical Aspects and Epidemiology of Child Abuse, 39 PEDIATRIC RADIOLOGY 457, 459 (2009) (referencing the "medial controversy" about "abuse in infants with head injury"); Paula Gerber \& Kathryn Coffman, Nonaccidental Head Trauma in Infants, 23 CHILD's NeRvous Sys. 499, 505 (2007) ("Nonaccidental head trauma in infants is the leading cause of infant death from injury. The high rate of repeated abuse 
of the SBS/AHT hypothesis. ${ }^{26}$ After the National Institutes of Health convened a conference in 2002 to consider the issues in SBS cases, the conference chair added a preface to the conference proceedings observing: "Because there is very little scientific experimental or descriptive work [on SBS], the pathophysiology remains obscure, and the relationship to mechanics even cloudier . . . . What we need is science-research and evidence that just isn't there right now." 27 Among the physicians recognizing the controversy is Dr. Norman Guthkelch, who forty years after first propounding the hypothesis observed that the "problem of potential child abuse . . . has caused a great deal of controversy since it was first described." ${ }^{28}$ Indeed, Dr. Guthkelch added, "While controversy is a normal and necessary part of

makes identification of potential cases crucial. The underlying biomechanics of injury in this syndrome and the purported sequelae of accidental and nonaccidental trauma remain controversial.”); D.M.B. Hall, The Future of Child Protection, 99 J. RoYAL SOC'Y OF MED. 6, 7 (2006) ("[A]reas of controversy include the diagnosis of child sexual abuse, the problem of 'shaken baby syndrome' and the extent to which abnormally fragile bones might account for unexplained fractures.”); Scott Denton \& Darinka Mileusnic, Delayed Sudden Death in an Infant Following an Accidental Fall: $A$ Case Report with a Review of the Literature, 24 AM. J. ForensiC MED. \& PATHOLOGY 371, 371 (2003) ("Several controversies exist regarding ultimately lethal head injuries in small children. Death from short falls, timing of head injury, lucid intervals, presence of diffuse axonal injury (DAI), and subdural hematoma (SDH) as a marker of DAI are the most recent controversial topics of debate in this evolving field of study.").

26. See, e.g., Carole A. Jenny et al., Biomechanical Response of the Infant Head to Shaking: An Experimental Investigation, 34 J. NEUROTRAUMA 1, 1 (2017) ("Controversy exists regarding whether violent shaking is harmful to infants in the absence of impact."); Matthieu Vinchon, Reply to Pr Charles Hyman: The Scientific Controversy Over Abusive Head Trauma in Infants, 27 CHILD’s Nervous Sys. 203, 203 (2011) ("We are well aware of the controversial nature of the series of papers . . . published by our team in Child's Nervous System on the topic of infantile head injuries . . . ."); Christopher S. Greeley, A Witnessed Short Fall Mimicking Presumed Shaken Baby Syndrome (Inflicted Childhood Neurotrauma), 44 PEDIATRIC NEUROSURGERY 90, 90 (2008) ("It is refreshing to see controversial topics addressed in the medical literature in such a balanced fashion. This will hopefully result in furthering our understanding of some of the controversies in inflicted brain injury and fewer unsupported opinions in legal proceedings.”); Kent P. Hymel, Carole Jenny, \& Robert W. Block, Intracranial Hemorrhage and Rebleeding in Suspected Victims of Abusive Head Trauma: Addressing the Forensic Controversies, 7 ChILD MALTREATMENT 329 (2002); Mark S. Dias, Inflicted Head Injury: Future Directions and Prevention, 13 Neurosurgery Clinics N. AM. 247, 247 (2002) ("Despite the explosion of interest and the clarification of certain features, many unanswered questions remain [about AHT]. Some of the answers to these questions are difficult or even impossible to obtain, because the medical facts are, by nature, uncertain or unreliable in many cases.").

27. Carole E. Nicholson, Preface to Inflicted Childhood Neurotrauma, at ix (Robert M. Reece \& Carol E. Nicholson eds., 2003) (publishing the conference proceedings).

28. A.N. Guthkelch, Problems of Infant Retino-Dural Hemorrhage with Minimal External Injury, 12 Hous. J. HeAlth L. \& PoL'Y 201, 201 (2012). 
scientific discourse, there has arisen a level of emotion and divisiveness on shaken baby syndrome/abusive head trauma that has interfered with our commitment to pursue the truth." 29

\section{B. Controversy in the Biomechanical and Scientific Literature}

When one expands review of the literature to other relevant fields-most notably biomechanics-the depth of the controversy becomes even clearer. ${ }^{30}$ As the SPR acknowledges, virtually all of the biomechanical research has concluded that even the most vigorous shaking cannot generate sufficient forces to reach estimated brain injury thresholds. ${ }^{31}$ The biomechanical research, for example, reveals that vigorous shaking generates accelerations roughly equivalent to a onefoot fall onto carpet, ${ }^{32}$ and a fall of just three to four feet generates at least ten times the load of the most violent shaking, well within injury thresholds. ${ }^{33}$ The SPR's response, however, is not to acknowledge that this creates serious doubt-and hence controversy-about pure shaking as a mechanism of injury, but to reject the biomechanical research because it does not comport with these physicians' view of reality. ${ }^{34}$

29. Id.

30. See, e.g., D.R. Wolfson, D.S. McNally, M.J. Clifford \& M.Vloeberghs, Rigid-Body Modelling of Shaken Baby Syndrome, 219 J. EngINEERING MED. 63, 66 (2005) ("There is still controversy as to the mechanisms of injury, specifically the requirement for impact.").

31. See, e.g., Ann-Christine Duhaime et al., The Shaken Baby Syndrome: A Clinical, Pathological and Biomechanical Study, 66 J. Neurosurgery 409, 414 (1987); Michael T. Prange et al., Anthropomorphic Simulations of Falls, Shakes, and Inflicted Impacts in Infants, 99 J. NeUROSURGERY 143, 149 (2003). Only two outlier biomechanical investigations suggest that violent shaking might possibly generate sufficient accelerations to produce significant brain injury, but in both cases those accelerations were achieved only with impact, and both articles have been subject to considerable criticism. Compare Jenny et al., supra note 26 and C.Z. Cory \& M.D. Jones, Can Shaking Alone Cause Fatal Brain Injury?: A Biomechanical Assessment of the Duhaime Shaken Baby Syndrome Model, 43 MED. SCI. \& L. 317 (2003), with Dutch Johnson \& Roland N. Auer, Response to Jenny et al. (DOI: 10.1089/neu.2016.4687): Biomechanical Response of the Infant Head to Shaking: An Experimental Investigation, 35 J. NEURotrama 1045 (2018).

32. Prange et al., supra note 31, at 146-49.

33. A.K. Ommaya et al., Biomechanics and Neuropathology of Adult and Paediatric Head Injury, 16 Brit. J. NeUROSURGERY 220, 226 (2002).

34. For example, when confronted with the biomechanical research that indicates that shaking alone cannot cause the injuries and findings ascribed to SBS, Dr. Jill Glick, Professor of Pediatrics at the University of Chicago, testified in 2009 that "the whole point of biomechanic studies is to create what we know happens in nature and ... biomechanic models have yet to recreate what happens in nature and once those biomechanic models create what we know happens, they will be very valuable for us . . . but we do know that children are shaken and have traumatic brain injury. . . . Not saying that every child with that trauma is shaken. I'm just saying that those that are shaken have been and so if we can't create that in the lab then the lab really doesn't 
While there are indeed methodological challenges with the biomechanical research, ${ }^{35}$ no one has yet explained why or how the modeling might be so far off target as to produce the conclusions it has to date, and no one has produced other models and defensibly estimated injury thresholds to establish that shaking can cause such injuries. Biomechanics, as a whole, quite consistently alone creates the scientific controversy that the SPR prefers that courts not notice. ${ }^{36}$

SBS/AHT proponents respond that, even if shaking alone cannot cause such injuries, there is no dispute that shaking with impact can (hence the name change from SBS to AHT) ${ }^{37}$ That is certainly true. But that does not resolve the controversies. For if impact can cause these injuries and the constellation of medical findings-and the biomechanical research confirms that it can-then is shaking even relevant? And if impacts can cause these injuries, how can medicine purport to distinguish between inflicted and accidental impacts, such as the impact from a short fall, or those involving and not involving shaking? Indeed, the biomechanical research shows not only that shaking is an unlikely mechanism for these injuries, but also that even the most vigorous shaking generates one-fiftieth of the force of shortdistance falls, such as accidental falls from furniture (beds, couches, changing tables, etc.). ${ }^{38}$ To rely on brain and eye injuries to diagnose SBS or AHT, despite a caregiver's report of a short fall (as happens with some regularity), is inherently controversial, given that the

tell us much." Testimony of Dr. Jill Glick in Transcript of Trial at 35-36, People $v$. Rieken, No. 05-CF-75 (Ill. Cir. Ct. Feb. 19, 2005).

35. Biomechanical research utilizes dummies (such as crash test dummies), animal tests, cadaver tests, and computer simulations, and none are of course perfectly representative of the human infant body (although they are routinely accepted for research in other safety areas, such as automobile, playground, and sports equipment safety). See, e.g., Faris A. Bandak, Shaken Baby Syndrome: A Biomechanics Analysis of Injury Mechanisms, 151 ForENSIC SCI. INT'L 71, 71 (2005). Moreover, it is true that infant brain injury thresholds in this research are based in part on estimates and scaling from known adult injury thresholds, while the infant brain is not just a miniature adult brain. But the research is nonetheless well-grounded in established techniques, and no one has yet marshaled an argument to support a conclusion that the estimated infant injury thresholds are off by such a significant magnitude as to overcome the conclusions of the research-that shaking alone cannot cause the injuries ascribed to it by the SBS hypothesis.

36. See, e.g., R.W.G. Anderson et al., Biomechanical Studies in an Ovine Model of Non-Accidental Head Injury, 47 J. BIOMECHANICS 2578, 2578 (2014) ("Many aspects of NAHI remain controversial and intermittently undergo revision . . . including whether shaking alone is sufficient to injure the brain or whether an additional head impact is required.").

37. Id.

38. Duhaime et al., supra note 31, at 413. See also Prange et al., supra note 31 (explaining that the peak rotational accelerations for a shake are less than those in a one-foot fall on to carpet). 
biomechanical research so strongly points to the short fall as the much more plausible cause of the injuries. ${ }^{39}$

\section{Uncertainty about SBS Mechanisms and Conclusions}

In the end, to suggest that there is no controversy, given how little is understood about the mechanism and pathophysiology of infant brain injury in these cases, is to defy both reality and reason. Yet one area in which there is true agreement is that these matters are not well understood. ${ }^{40}$ Controversy under these circumstances is inevitable, and it is indeed healthy for the development of scientific knowledge.

Whenever a medical conclusion lacks gold-standard (or even somewhat-defined) criteria, the conclusion is inherently controversialat least in the sense that different physicians will interpret the presenting signs in different ways and will disagree about specific cases. And yet everyone agrees that there are no gold-standard criteria for SBS or AHT. ${ }^{41}$ That concession is indeed part of the reason why the SPR (and other SBS/AHT-hypothesis proponents) now go to such lengths to distance themselves from the classic triad-the presence of subdural hematoma, retinal hemorrhages, and encephalopathy or cerebral edema-as a valid standard, and to argue that the triad is a "straw man" and a defense construct. ${ }^{42}$

In that regard, the SPR engages in more than a bit of revisionist history, as the "triad" was not constructed by defense lawyers but by

39. Prange et al., supra note 31.

40. See, e.g., Costine-Bartell et al., supra note 25, at 816 ("Although the exact etiologic mechanisms that cause injury in children with AHT remain controversial, repetitive motions attempting to model aspects of shaking have been employed in some animal models to investigate injury, but none has resulted in the extensive SDH nor the widespread hypoxic-ischemic type damage observed after the more severe forms of AHT in children."); id. at 830 ("The exact pathophysiological mechanisms by which widespread unilateral hemispheric hypoxic-ischemic injury is initiated and propagated in children are not fully understood, but similar findings were produced in this model in the absence of angular acceleration/deceleration."); Gil Binenbaum et al., Retinal Hemorrhage and Brain Injury Patterns on Diffusion-Weighted Magnetic Resonance Imaging in Children with Head Trauma, 17 J. AAPOS 603, 603 (2013) (team of SBS/AHT adherents acknowledging that " $[\mathrm{t}]$ here are currently multiple hypothesized factors in the pathogenesis of brain pathology and retinal hemorrhage in abusive head trauma . . . [and] the relative importance of these factors cannot be determined precisely based on the published data."); id. at 604 (asserting an association between retinal hemorrhages and AHT but acknowledging, "however, the mechanisms underlying retinal hemorrhages are still not clearly established").

41. See, e.g., Kent P. Hymel et al., Derivation of a Clinical Prediction Rule for Pediatric Abusive Head Trauma, 14 Pediatric CRitical CARE MED. 210, 212, 217 (2013) ("Gold standard definitional criteria for AHT do not exist. . . . [I]n the absence of a gold standard, clinicians rarely confirm or exclude AHT with complete certainty and are compelled instead to adopt a probabilistic approach to the diagnosis.").

42. Choudhary, supra note 10 , at 1050. 
child abuse physicians and prosecutors. ${ }^{43}$ For many years those SBShypothesis proponents wrote,${ }^{44}$ taught,${ }^{45}$ and testified ${ }^{46}$ that the presence

43. See P.G. Richards et al., Shaken Baby Syndrome, 91 ARCHIVES DiSEASE CHILDHOOD 205, 205 (2006).

44. See, e.g., David L. Chadwick et al., Shaken Baby Syndrome-A Forensic Pediatric Response, 101 Pediatrics 321, 321 (1998) (describing a letter published by seventy-two leading child abuse pediatricians asserting that SBS "is now a wellcharacterized clinical and pathological entity with diagnostic features in severe cases virtually unique to this type of injury-[1] swelling of the brain (cerebral edema) secondary to brain injury, [2] bleeding within the head (subdural hemorrhage), and [3] bleeding in the interior lining of the eyes (retinal hemorrhages).”); Jeffrey M. Jentzen, Pathological Findings in Fatal Shaken Impact Syndrome, in THE SHAKEN BABY SyndROME: A MultidisciplinARY APPROACH 199, 201 (Stephen J. Lazoritz \& Vincent J. Palusci eds., 2001) ("[The] classical findings of retinal hemorrhages, subdural hematoma, and brain swelling cannot be fully explained by any other medical entity."); B. Harding, R. Anthony Risdon, \& Henry F. Krous, Shaken Baby Syndrome: Pathological Diagnosis Rests on the Combined Triad, not on Individual Injuries, 328 BRIT. MED. J. 720, 720 (2004); Richards et al., supra note 43 ("The triad of encephalopathy, subdural haemorrhages, and retinal haemorrhages as an indicator of head injury has stood the test of time."); Matthieu Vinchon et al., Confessed Abuse Versus Witnessed Accidents in Infants: Comparison of Clinical, Radiological, and Ophthalmological Data in Corroborated Cases, 26 CHILD's Nervous Sys. 637, 637 (2010) ("The hallmarks of shaken baby syndrome (SBS) are subdural hematomas (SDH), encephalopathy, and retinal hemorrhage (RH).”); Brian K. Holmgren, Prosecuting the Shaken Infant Case, in THE SHAKEN BABY Syndrome: A Multidisciplinary APPROACH 275, 319 (Stephen J. Lazoritz \& Vincent J. Palusci eds., 2001) ("The expert who acknowledges the classic findings of SBS including subdural hematoma, retinal hemorrhage and edema, but chooses to ignore this constellation of findings in favor of an alternative hypothesis will appear foolish."); Paula Gerber \& Kathryn Coffman, Nonaccidental Head Trauma in Infants, 23 CHILD's Nervous Sys. 499, 499 (2007) ("Clinical features that suggest inflicted head trauma include the triad of the so-called shaken baby syndrome, consisting of retinal hemorrhage, subdural, and/or subarachnoid hemorrhage in an infant with little signs of external trauma.").

45. For example, authoritative child-abuse textbooks in the late 1990s and early 2000s acknowledged the triad and declared it in its complete form to be pathognomonic (distinctively characteristic) of SBS. See Robert A. Kirschner, The Pathology of Child Abuse, in THE BATTERED ChILD 272-73 (Mary Edna Helfer et al. eds., 5th ed. 1997) ("SBS usually produces a diagnostic triad of injuries . . . [which] must be considered virtually pathognomonic of SBS in the absence of documented extraordinary blunt force such as an automobile accident."); Kenneth W. Reichert \& Meic Schmidt, Neurologic Sequelae of Shaken Baby Syndrome, in THE SHAKEN BABY Syndrome: A Multidisciplinary ApProACH 79, 83 (Stephen Lazoritz \& Vincent J. Palusci eds., 2001) ("For all practical purposes, however, retinal hemorrhages in association with acute subdural hemorrhaging means that a violent shaking with or without impact occurred."); Robert H. Kirschner \& Harry Wilson, Pathology of Fatal Abuse, in Child Abuse: Medical Diagnosis and Management 503 (Robert M. Reece \& Stephen Ludwig eds., 2d ed. 2001) ("Shaken Baby Syndrome . . . usually produces a triad of injuries that includes cerebral edema, subdural hemorrhage, and retinal hemorrhages. No other medical condition fully mimics all of its features."). See also Rob Parrish, Executive Summary of the Third National Conference on Shaken Baby Syndrome 1 (2000), https://www.dontshake.org/media/k2/attachments/2000SaltLakeCityProgram.pdf [https://perma.cc/S9P7-5U8P] ("Often referred to as the 
of the "triad" - and sometimes even single elements of the triad ${ }^{47}$-were pathognomonic for abuse. ${ }^{48} \mathrm{We}$ are gratified to see that, today, proponents of the SBS/AHT hypothesis acknowledge that neither the triad nor any other specific findings can be relied upon conclusively to diagnose abuse. ${ }^{49}$ That is scientific progress, and it resolves one area of dispute-but by no means all, for it now creates other controversies about what physicians can rely upon to diagnose abuse.

Yet even SBS/AHT hypothesis proponents acknowledge that, in the absence of agreed-upon criteria, the determination is inherently controversial and difficult. As Leventhal and colleagues have observed, "Making or refuting a diagnosis of abusive head trauma is challenging." 50 Leventhal bemoans this reality as one of the "key challenges" facing physicians when evaluating young children for abuse. ${ }^{51}$ Leventhal observes:

'triad,' the consensus appears to be that a collection of (1) damage to the brain, evidenced by severe brain swelling and/or diffuse traumatic axonal injury; (2) bleeding under the membranes which cover the brain, usually subdural and/or subarachnoid bleeding; and, (3) bleeding in the layers of the retina, often accompanied by other ocular damage, when seen in young children or infants, is virtually diagnostic of severe, whiplash shaking of the head.").

46. See Deborah Tuerkheimer, Flawed Convictions: "Shaken Baby SYNDROME" AND THE INERTIA OF INJUSTICE 7-12, 31-44 (2014) (citing examples of courtroom testimony).

47. See, e.g., Arthur B. Eisenbrey, Retinal Hemorrhage in the Battered Child, 5 CHILD's BRAIN 40, 42 (1979) (“[R]etinal hemorrhage in children under [three] with or without other evidence of injury is pathognomonic of the battered child syndrome."); J.E. Carter \& A.Q. McCormick, Whiplash Shaking Syndrome: Retinal Hemorrhages and Computerized Axial Tomography of the Brain, 7 CHILD ABUSE \& NEGLECT 279, 280 (1983) (“[B]ilateral extensive pale-centered retinal hemorrhages . . . are considered pathognomonic of the syndrome of whiplash shaking injury and of child abuse."); RoB PARrish, U.S. DEP'T OF Just., BATTEREd ChIld Syndrome: InVestigating Physical Abuse AND Homicide 8 (4th prtg. 2002) (“According to all credible studies in the past several years, retinal hemorrhage in infants is, for all practical purposes, conclusive evidence of shaken baby syndrome in the absence of a good explanation," such as severe automobile accidents and falls from several stories onto a hard surface.). See also PAPETTI, supra note 24, at $51 \mathrm{n} .175$ (citing literature and case testimony claiming SBS diagnosis on the basis of one or two features of the triad).

48. See Papetti, supra note 24, at 54 n.183 (citing much of the literature in which the triad was deemed essentially pathognomonic for SBS/AHT).

49. See, e.g., Sandeep Narang, A Daubert Analysis of Abusive Head Trauma/Shaken Baby Syndrome, 11 Hous. J. HeAlth L. \& POL'y 505, 571 (2011) ("However, the mere presence alone of SDHs and RHs does not establish a diagnosis of AHT.").

50. John M. Leventhal et al., Diagnosing Abusive Head Trauma: The Challenges Faced by Clinicians, 44 Pediatric Radiology (Special Issue: Abusive HeAd Trauma) S537, S541 (2014).

51. Id. at $\mathrm{S} 538$. 
A . . challenge occurs when families receive dissimilar information from different clinicians about the likelihood of abuse. When some clinicians tell families that they are concerned about abuse and other clinicians indicate that abuse is being ruled out or that the child is cleared, families may not only become confused, but also have a tendency to split the clinicians into good and bad ones. These inconsistencies in how clinicians discuss the likelihood of abuse with families help reinforce the view that the caregiver did nothing wrong and that the physicians cannot even decide if the child was abused. ${ }^{52}$

No wonder physicians who style themselves as child-abuse specialists want to deny the validity of any disagreements or controversies, and attempt to silence or delegitimize all who disagree.

\section{Controversy in the Face of Claimed Consensus}

Publication of the SPR "consensus" statement does not resolve the controversies. It is dangerous and inappropriate to suggest that, because the SPR has published a statement proclaiming consensus among pediatric radiologists, the matters are settled and free of all controversy. As has been widely observed, "[s]cience is not a democracy." ${ }^{53}$ Moreover, under the regime created by Daubert, the mere say-so of a guild of experts, no matter how unified they might be, is never enough, in law or in science; what matters is whether the scientific claims are adequately supported by scientific evidence. As one of us observed some years ago:

The guild test does at least claim to deal with reliability of the process beyond individual experience, but the reliability judgment is delegated to a group that, by definition, already believes in the process. The guild test trades the ipse dixit of the individual for the ipse dixit of the group. ${ }^{54}$

Or as Dr. Norman Guthkelch observed in 2012, "the issue is not what the majority of doctors (or lawyers) think but rather what is

52. Id.

53. Jacek Z. Kubiak, Science is Not a Democracy, 50 INT'L J. DeVelopmental Biology 586, 587 (2006).

54. D. Michael Risinger, Defining the "Task at Hand": Non-Science Forensic Science after Kuhmo Tire Co. v. Carmichael, 57 WASH. \& LEE L. REV. 767, 777 (2000). 
supported by reliable scientific evidence . . ." ${ }^{55}$ And as the authors of a recent Swedish government report on the weak scientific foundation for the SBS hypothesis put it, "we need to distinguish between evidence-based knowledge and state-of-the-art consensus and, if we expect to achieve a reflective equilibrium, then the consensus should be adapted to the evidence and not vice-versa." 56

In any event, one should not be misled by the claim that the SPR statement truly reflects "consensus," at least not in the way the word ordinarily suggests. The "consensus" statement was not approved or even voted upon by all, or even a majority, of the membership of the SPR.$^{57}$ It was not even subjected to debate by the membership. ${ }^{58}$ It was, instead, the product of a small group of true-believers in SBS/AHT, appointed by the SPR's governing body. Of the committee's fifteen members, almost all had previously staked out published opinions defending the SBS/AHT hypothesis or attacking its critics, ${ }^{59}$ several are

55. Gut hkelch, supra note 28, at 207-08. See also Christopher Milroy, Foreward to RANDy PAPeTti, The Forensic UnReliability of THE SHAKEN BABy SYNDROME, at xiii (2018) ("[T]hese issues should not turn on past or even current acceptance of SBS and AHT beliefs among physicians; these are matters or reliability, not popularity.").

56. Niels LynØe \& Anders Eriksson, Consensus Should be Adapted to the Evidence and not Vice-Versa, 107 ACTA PÆDIATRICA 1476, 1476 (2018).

57. Two of us (Barnes and Mack) are members of the SPR, received the initial draft, and provided written feedback, but were never offered an opportunity to vote on the paper before it was issued. Nor was their written response ever published or shared with the general membership of the SPR.

58. Id . Nor were Barnes and Mack, as members of the SPR, invited to participate in any discussion among the membership, beyond the opportunity to submit their ignored response letter.

59. See, e.g., Dawn Saunders, Maria Raissaki, Sabah Servaes, Catherine Adamsbaum, Arabinda Kumar Choudhary, Joëlle Anne Moreno, Rick R. van Rijn, Amaka C. Offiah, Throwing the Baby out with the Bath Water-Response to the Swedish Agency for Health Technology Assessment and Assessment of Social Services (SBU) Report on Traumatic Shaking, 47 Pediatric Radiology 1386, 1388 (2017); Thomas. L. Slovis et al., The Creation of Non-Disease: An Assault on the Diagnosis of Child Abuse, 42 Pediatric Radiology 903, 903 (2012); Robert W. Block \& Vincent J. Palusci, Child Abuse Pediatrics: A New Pediatric Subspecialty, 148 J. Pediatrics 711, 711 (2006); Gary L. Hedlund \& Lori D. Frasier, Neuroimaging of Abusive Head Trauma, 5 Forensic SCI. Med. \& PATHology 280, 281 (2009); Narang, supra note 49; Mark S. Dias, The Case for Shaking, in Child Abuse And Neglect: Diagnosis, Treatment, And Evidence 364, 364-65 (Carole Jenny ed., 2011); Christian \& Block, supra note 1 (SPR "consensus" paper co-author highlighted in bold); V. Michelle Silvera et al., Retroclival Collections Associated with Abusive Head Trauma in Children, 44 Pediatric Radiology (Special Issue) S621, S630 (2014); Maura E. Ryan et al., ACR Appropriateness Criteria Head Trauma-Child, 11 J. AM. C. Radiology 939, 943 (2014); Elizabeth E. Gilles \& Marvin D. Nelson, Jr., Cerebral Complications of Nonaccidental Head Injury in Childhood, 19 PEDIATRIC NEUROLOGY 119, 125 (1998). Individuals highlighted in bold were co-authors of the SPR "consensus" paper. 
not radiologists, but child-abuse pediatricians ${ }^{60}$ and a pediatric neurosurgeon ${ }^{61}$ who are all leading advocates of the hypothesis, and one is not a physician, ${ }^{62}$ but is instead the only law professor who has published widely in support of the hypothesis ${ }^{63}$ and against the growing body of legal scholarship ${ }^{64}$ and judicial decisions ${ }^{65}$ that challenge the hypothesis or the definitiveness of the "diagnosis."

Moreover, the process leading to the publication of the SPR statement appears to have been designed to eliminate the possibility of real debate and disagreement. The statement claims to have undergone a "rigorous" consensus process, including dissemination to the SPR's membership "for comment and if necessary further revisions." ${ }^{66}$ But the membership first received notice of this document on October 17, 2017, when they received an email accompanied by a fifty-page, 211-

60. Sandeep K. Narang and Cindy W. Christian.

61. Mark S. Dias.

62. Joëlle Anne Moreno, J.D., Florida International College of Law. Professor Moreno's participation as a co-author further confirms the essentially legal nature of the paper and the purported "diagnosis."

63. See Joëlle Anne Moreno \& Brian Holmgren, Dissent into Confusion: The Supreme Court, Denialism, and the False "Scientific" Controversy over Shaken Baby Syndrome, 2013 UtAH L. REV. 153; Joëlle Anne Moreno \& Brian Holmgren, The Supreme Court Screws Up the Science: There Is No Abusive Head Trauma/Shaken Baby Syndrome "Scientific" Controversy, 2013 UTAH L. REV. 1357.

64. See Findley et al., supra note 3, at 241-43, 305; TUERKHEIMER, supra note 46, at 17-31; Deborah Tuerkheimer, The Next Innocence Project: Shaken Baby Syndrome and the Criminal Courts, 87 WASH. U. L. REV. 1, 16-17 (2009); Deborah Tuerkheimer, Science-Dependent Prosecution and the Problem of Epistemic Contingency: A Study of Shaken Baby Syndrome, 62 ALA. L. REV. 513 (2011); Keith A. Findley \& D. Michael Risinger, The Science and Law Underlying Post-Conviction Challenges to Shaken Baby Syndrome Convictions: A Response to Professor Imwinkelried, 48 Seton Hall L. ReV. 1209. 1211-13 (2018); Deborah W. Denno, Concocting Criminal Intent, 105 GEo. L.J. 323 (2017); Caitlin M. Plummer \& Imran J. Syed, "Shifted Science" Revisited: Percolation Delays and the Persistence of Wrongful Convictions Based on Outdated Science, 64 CLEV. ST. L. REV. 483 (2016); Eza Bella Zakirova, Shaken Baby Syndrome: As a Controversy in Wrongful Conviction Cases, 81 ALB. L. REV. 1027 (2017-18); Keith Findley et al., Examining Shaken Baby Syndrome Convictions in Light of New Medical Scientific Research, 37 OKLA. CITY U. L. REV. 219 (2012); Edward J. Imwinkelried, Shaken Baby Syndrome: A Genuine Battle of the Scientific (and Non-Scientific) Experts, 46 Crim. L. Bull. 156 (2010); Molly Gena, Comment, Shaken Baby Syndrome: Medical Uncertainty Casts Doubts on Convictions, 2007 Wis. L. REv. 701; Lauren Quint, Note, Bridging the Gap: An Application of Social Frameworks Evidence to Shaken Baby Syndrome, 62 HaSTINGS L.J. 1839 (2011); Rachel Burg, Note, Un-Convicting the Innocent: The Case for Shaken Baby Syndrome Review Panels, 45 U. Mich. J.L. Reform 657 (2012); Genie Lyons, Comment \& Note, Shaken Baby Syndrome: A Questionable Scientific Syndrome and a Dangerous Legal Concept, 2003 UtAH L. REV. 1109; Daniel G. Orenstein, Shaken to the Core: Emerging Scientific Opinion and Post-Conviction Relief in Cases of Shaken Baby Syndrome, 42 ARIZ. ST. L.J. 1305 (2011).

65. See cases cited supra note 4.

66. Choudhary et al., supra note 10, at 1058 tbl.6. 
reference version of the "consensus statement." ${ }^{67}$ The membership was invited to submit responses, but was given only ten days, until October 27,2017 , for any such responses. ${ }^{68}$ Despite the shortness of this time, at least two prominent members of the SPR (and co-authors of this response)-Dr. Patrick D. Barnes at Stanford and Dr. Julie A. Mack at Pennsylvania State University-managed to submit a substantive, fourpage, single-spaced response, identifying numerous areas of disagreement and concern. ${ }^{69}$ In their letter, Drs. Barnes and Mack also wrote that, "[b]ecause of the short timeframe for comment, which is limited to SPR members, our feedback is abbreviated." ${ }^{70}$ They added that they were providing "these preliminary comments to meet the October 27 deadline, but ask for an opportunity to submit a more complete response." 71 If the consensus statement were to be published, they added, "we ask that the response be published with the Statement or shortly thereafter. We also recommend that comments be invited from other interested parties." 72 The SPR ignored the letter and each of its requests, and proceeded to publish the statement, proclaiming "consensus." 73

The SPR also cites a survey of physicians likely to be involved in diagnosing SBS/AHT to claim strong support for the diagnosis. ${ }^{74}$ The survey reports strong support among child-abuse physicians for the SBS/AHT diagnosis. ${ }^{75}$ That finding is hardly surprising, however, since the survey was targeted to those physicians "most commonly involved in suspected AHT cases." 76

Even within this survey, however, the data shows that one group of physicians-the group actually trained to assess cause of death, pathologists-diverges from the other physicians in their views about SBS and AHT. Among the relatively small cohort of pathologists included in this survey $(n=27)$, fewer than half, only 40.7 percent (eleven of twenty-seven) responded yes when asked if SBS is a valid

67. Letter dated from Drs. Patrick D. Barnes \& Julie A. Mack to the Society for Pediatric Radiology (Oct. 27, 2017) (on file with the authors). The letter is attached in full as Appendix 1 to this Article.

68. Id.

69. Id.

70. Id.

71. Id.

72. Id.

73. See Choudhary et al., supra note 10.

74. Id. at 1058 (citing Sandeep K. Narang et al., Acceptance of Shaken Baby Syndrome and Abusive Head Trauma as Medical Diagnoses, 177 J. Pediatrics 273 (2016)).

75. Id. at 1049-50.

76. Sandeep K. Narang et al., Acceptance of Shaken Baby Syndrome and Abusive Head Trauma as Medical Diagnoses, 177 J. Pediatrics 273, 274 (2016). 
diagnosis; the remainder-the majority-were divided evenly between saying no and that they did not know or were unsure. ${ }^{77}$ A much higher percentage of pathologists-92.6 percent-responded that the broader diagnosis, AHT, is valid, but that tells us only that they believe that abusive head trauma (which would include blunt force trauma to the head) exists (which no one doubts in the abstract); it tells us nothing about whether these pathologists believe they can reliably determine AHT caused by shaking or shaking with impact on the basis of a few brain and eye findings, whether they can reliably rule out alternative causes, whether children so abused can experience a lucid interval before collapse, etc.-that is, it tells us nothing about the subset of issues on which there is real controversy in AHT. ${ }^{78}$ Elsewhere, other survey research suggests that the controversy is indeed widespread among pathologists. ${ }^{79}$ And note that this survey tells us nothing about the views of the other group of scientists whose research overwhelmingly challenges the SBS/AHT hypothesis-the biomechanical engineers; they were not included in the survey at all. This survey simply does not prove an absence of controversy in the relevant scientific community taken as a whole.

Moreover, while the survey shows high levels of support among child-abuse physicians for the belief that SBS and AHT are valid diagnoses, and that shaking with or without impact is likely or highly likely to cause subdural hematomas, retinal hemorrhages, and coma or death, the survey masks nuances that lie at the heart of the real controversies.

First, it is worth noting that even among this group of physicians, belief in SBS/AHT is not universal-eighty-eight percent endorsed SBS as a general proposition and ninety-three percent endorsed AHT as a general proposition. ${ }^{80}$ Second, among these physicians, more reported believing that shaking with impact was likely to produce subdural hematoma, retinal hemorrhage, and coma or death than believed that shaking alone could cause each of these outcomes. ${ }^{81}$ Indeed, even

77. Id. at 277 .

78. Id.

79. See Stephen J. Cina, Controversies in Forensic Pathology: Results of a 2010 Survey of NAME Fellows, 2 ACAdem. Forensics Pathology 150, 151 (2012) (on-line survey data showing that by 2010 more than one-third of surveyed medical examiners no longer believed that it was even "possible to cause lethal closed head injuries in a small child by shaking alone"-let alone that they could diagnose abuse on the basis of the triad or related medical findings).

80. Narang et al., supra note 76, at 275.

81. For example, just under ninety percent believed that shaking with impact was likely or highly likely to produce subdural hematoma compared to approximately eighty-three percent for shaking alone. And while approximately eighty-nine percent believed that shaking with impact was likely or highly likely to lead to coma or death, 
among this group, fewer than eighty percent reported believing that pure shaking without impact is likely or highly likely to produce coma or death. ${ }^{82}$ Clearly, even among this group of child-abuse physicians, the matters are not free from controversy.

Second, even among the group who responded that pure shaking or shaking with impact was likely to produce subdural hematoma, retinal hemorrhage, and coma or death, this survey does not tell us whether these physicians believe that they can reliably "diagnose" SBS/AHT based on any individual or particular collection of these findings. Nor does it tell us other important but more nuanced specifics, such as whether these physicians believe that injury caused by shaking would also necessarily produce neck or spinal cord injury (which is rarely seen in SBS/AHT). Yet questions like these are where the controversies are most pronounced.

Finally, it is difficult to know exactly what to make of some of the survey results. The survey shows, for example, that only 3.1 percent of responding physicians reported a belief that short falls are likely or highly likely to result in death or coma. ${ }^{83}$ Given that short-fall deaths are now widely recognized in the literature and in well-documented case reports (including videotaped short-fall deaths), ${ }^{84}$ it is hard to believe that nearly ninety-seven percent of responding physicians believe that short falls cannot kill. Rather, it seems more likely that many respondents were interpreting this question to assess the likelihood that a death in any given case might have been the result of a short fall, given that everyone agrees that short-fall deaths are rare. But child deaths resulting from abuse that leaves no external injury are also rare. The real controversy, then, is how rare such short-fall deaths are, and how physicians can distinguish between cases where a reported short fall was the cause of a child's coma or death and those in which it was not. Again, that is where the real controversy lies; this survey masks that real controversy.

fewer than eighty percent believed that shaking alone could produce such consequences. Id. at 276.

82. Id.

83. Id.

84. See, e.g., John Plunkett, Fatal Pediatric Head Injuries Caused by ShortDistance Falls, 22 Am. J. Forensic Med. \& PATHology 1 (2001); John R. Hall et al., The Mortality of Childhood Falls, 29 J. Trauma 1273 (1989); Patrick E. Lantz \& Daniel E. Couture, Fatal Acute Intracranial Injury, Subdural Hematoma, and Retinal Hemorrhages Caused by Stairway Fall, 56 J. ForensiC SCI. 1648 (2011); David L. Chadwick et al., Annual Risk of Death Resulting From Short Falls Among Young Children: Less Than 1 in 1 Million, 121 PEDIATRICS 1213 (2008). 


\section{E. Broad Claims, Nuanced Controversies}

As this discussion suggests, to some extent the question about whether there is controversy depends on what the precise proposition is that is at issue. In this regard, the SPR statement is misleading. The SPR claims that there is no dispute about the validity of the AHT conclusions. If by this the SPR means that there is no dispute that AHT occurs-that is, that adults can cause brain injuries to infants and toddlers by physically abusing them, and that such abuse will sometimes produce medically recognizable signs (even if they are not specific for abuse)-then there is indeed no dispute. No one disputes that child abuse is real. ${ }^{85}$ Hence, the SPR misleads when it repeatedly labels the critics of the SBS/AHT hypothesis as "denialists." The SPR cites no literature or courtroom testimony-and none can be found-in which any of the SBS/AHT critics denies that abusive head trauma and other forms of child abuse are real, or even that violently shaking a child is an unsafe thing to do.

But that does not mean there are no disputes. What is in disputegiven the lack of any "gold-standard" criteria for AHT, and the undeniable reality that all of the physical findings also have multiple non-abusive etiologies-is whether physicians can reliably determine the existence of SBS or AHT primarily on the basis of brain, eye, and related findings. Also in dispute is whether shaking alone can cause the serious brain injuries typical in these cases, at least without also causing massive neck injury (which, again, is almost never present ${ }^{86}$ ), and a host of subsidiary questions, such as the mechanism of the injury (e.g., is subdural hemorrhage the product of torn bridging veins or is it the product of bleeding from the numerous more fragile vessels in the dura; is the encephalopathy the product of physical tearing of nerves, or does it arise from hypoxia-ischemia? ${ }^{87}$ ), how to interpret the possibility of alternative causes of injury, whether a child could have experienced a significant period of lucidity between injury and collapse, and the like. ${ }^{88}$ Those are serious scientific questions, not the thoughtless dismissiveness of "denialists."

85. See Papetti et al., supra note 24, at 311-12.

86. See Robert M. Reece, Controversies in Shaken Baby/Shaken Impact Syndrome, in The Shaken BABy Syndrome: A Multidisciplinary ApProACH 384 (Stephen Lazoritz \& Vincent J. Palusci eds., 2001) ("Injuries to the neck muscles or cervical vertebrae are distinctly uncommon in SBS/SIS."); see also PAPETTI, supra note 24, at $51 \mathrm{n} .175$ (citing literature and cases).

87. See Papetti et al., supra note 24, at 320-33.

88. See Findley et al., supra note 3, at 245. 


\section{F. Recognizing Controversy: Independent Scientific Reviews}

Given all of the challenges to researching and diagnosing child abuse, it is no wonder that when independent scientists-those steeped in knowledge of and fidelity to rigorous scientific principles and methods-examine SBS/AHT, they find it wanting. The most notable among such inquiries was undertaken by the Swedish Agency for Health Technology Assessment and Assessment of Social Services (SBU). ${ }^{89}$ The SBU appointed a panel of leading pediatricians and experts in forensic medicine, radiology, medical epidemiology, and medical and research ethics to undertake a systematic review of the medical literature to assess the underlying strength of the SBS hypothesis and the diagnostic validity of the triad. ${ }^{90}$ After retrieving 3,773 medical papers and identifying 1065 of them as relevant, the SBU found that only thirty met the inclusion criteria of potentially providing evidence on the diagnostic value of the triad, ${ }^{91}$ and of those, only two were of moderate quality; none were of high quality; and all the rest were low quality. ${ }^{92}$ Hence, the SBU concluded, "There is insufficient scientific evidence on which to assess the diagnostic accuracy of the triad in identifying traumatic shaking (very low quality evidence)." 93 In particular, the SBU noted that, because the research base is riddled with methodological flaws, including massive circularity, the "[s]ensitivity, specificity and predictive values" produced by the research result in "incorrect conclusions" and "incorrect calculations of incidence." ${ }^{94}$ In sum, the SBU concluded that the evidentiary foundation for SBS is of "very low quality." 95

When SBS/AHT-supporting pediatricians, somewhat predictably, lashed out at the Swedish report, its authors responded, clarifying and re-emphasizing the weakness of the scientific basis for medical conclusions of SBS: "As the triad is a very important criterion used by child protection teams, the extremely high diagnostic accuracy of the

89. Swedish Agency for Health Technology Assessment and Assessment of Social Services, Traumatic Shaking: The Role of the Triad in Medical Investigations of Suspected Traumatic Shaking-A Systematic Review (2016) [hereinafter SBU Report], https://www.sbu.se/255e [https://perma.cc/J5YW-S53C].

90. See Måns Rosén et al., Shaken Baby Syndrome and the Risk of Losing Scientific Scrutiny, 106 ACTA PÆDIATRICA 1905 (2017).

91. SBU Report, supra note 89, at 17-22.

92. Id. at $22-25$.

93. Id. at 5 .

94. Id. at 30 .

95. Id. at 61 . 
triad is obviously not based on scientific criteria but rather on circular reasoning. In other words, it is a self-fulfilling prophecy." 96

Previously, in Canada, in 2008, the government of Ontario conducted an exhaustive inquiry into pediatric forensic pathology in the province. ${ }^{97}$ The product was a 674-page report, which became known as the Goudge Inquiry, after Court of Appeal Judge Stephen Goudge, who was Commissioner of the inquiry. ${ }^{98}$ The inquiry was instigated by concerns about the pediatric pathology system in general, and in particular about one apparently rogue pediatric forensic pathologistDr. Charles Smith-who dominated the field in Ontario for years. ${ }^{99}$ But in the course of investigating the field, the Goudge Inquiry identified the same potential problems with SBS that have fueled the debates elsewhere for the past two decades. The Report noted that "one of the deepest controversies surrounding pediatric forensic pathology concerns shaken baby syndrome," 100 and described the matter as "fraught with controversy." 101

Most recently, in the United States, in 2016, the President's Council of Advisors on Science and Technology (PCAST) - a group of respected scientists from a variety of disciplines-issued a report assessing the scientific status of a host of traditional forensic disciplines, focusing particularly on feature-comparison disciplines. ${ }^{102}$ Although SBS/AHT is not a feature-comparison discipline, PCAST was concerned enough about the scientific underpinnings of the SBS/AHT hypothesis that it observed: "PCAST notes that there are issues related to the scientific validity of other types of forensic evidence that are beyond the scope of this report but require urgent attention-including notably arson science and abusive head trauma commonly referred to as 'Shaken Baby Syndrome." "103 A medical conclusion truly well-

96. Niels LynØe et al., Authors' Overarching Reply to All the Responses Received to the Systematic Literature Review on Shaken Baby Syndrome, 106 ACTA PÆDIATRICA 1031, 1031 (2017).

97. Stephen T. Goudge, The Inquiry into Pediatric Forensic Pathology IN ONTARIO (2008), https://www.attorneygeneral.jus.gov.on.ca/inquiries/goudge/report/v1_en_pdf/Vol_1_E ng.pdf [https://perma.cc/JRJ8-788X].

98. Id.

99. Id. at 3-8.

100. Id. at 527 .

101. Id. at 528.

102. Executive Office of the President, President's Council of Advisors on ScIENCE AND TeChNOlogy, Report to the PRESIDENT, Forensic Science in Criminal Courts: Ensuring Scientific Validity of Feature COMPARISON METHODS (Sept. 2016), https://obamawhitehouse.archives.gov/sites/default/files/microsites/ostp/PCAST/pcast_ forensic_science_report_final.pdf [https://perma.cc/6AKM-LVJC].

103. Id. at 23 n. 15 . 
grounded in scientific research and free of significant doubt or controversy is hardly the kind of field whose "scientific validity" requires "urgent attention."

Again, the insights of Dr. Guthkelch are helpful:

"Getting it right" requires that we distinguish between hypotheses and knowledge. SBS and AHT are hypotheses that have been advanced to explain findings that are not yet fully understood. There is nothing wrong in advancing such hypotheses; this is how medicine and science progress. It is wrong, however, to fail to advise parents and courts when these are simply hypotheses, not proven medical or scientific facts, or to attack those who point out problems with these hypotheses or who advance alternatives. ${ }^{104}$

\section{G. Judicial Recognitions of the Shifting Science and Attendant Controversy}

In light of all these concerns, when courts have been pressed to assess the debates about SBS/AHT, most notably in postconviction proceedings in which the defendant seeks a new trial because new research reflects legitimate controversy while the state's evidence at trial presented the matters as settled science, they invariably find emerging and growing legitimate debate-or even that many aspects of the old SBS hypothesis have been proven false. ${ }^{105}$ The SPR would write these off as the decisions of guileless judges hoodwinked by deliberately misleading defense arguments and theories. But these decisions almost always issue after the court has heard extensive testimony from leading and knowledgeable experts on both sides of the debates, including extensive consideration of the relevant medical and scientific literature. And often their rulings are based on admissions that even prosecution experts have had to make about shifting understandings and evolving research in the field. While science can indeed be challenging for judges, these are not uninformed decisions.

In the first such case to recognize the controversies and overturn a conviction, for example, involving a respected and much-loved in-home daycare provider named Audrey Edmunds, the Wisconsin Court of Appeals vacated the conviction on the basis of new research challenging the triad-based medical-expert opinions that had formed the heart of the State's case at Edmunds's trial in $1997 .{ }^{106}$ The postconviction

104. Guthkelch, supra note 28, at 207.

105. See cases discussed supra note 4 and accompanying text.

106. See State v. Edmunds, 746 N.W.2d 590 (Wis. Ct. App. 2008). Full disclosure: One of us (Findley) was counsel for Edmunds in that case, and another 
proceedings nearly a decade later produced expert evidence from ten doctors-six for the defense and four for the State, over four days of testimony. ${ }^{107}$ Reviewing that record, the appellate court ruled that:

Edmunds presented evidence that was not discovered until after her conviction, in the form of expert medical testimony, that a significant and legitimate debate in the medical community has developed in the past ten years over whether infants can be fatally injured through shaking alone, whether an infant may suffer head trauma and yet experience a significant lucid interval prior to death, and whether other causes may mimic the symptoms traditionally viewed as indicating shaken baby or shaken impact syndrome. ${ }^{108}$

In Rochester, New York, in 2014, a court held a postconviction hearing spanning three weeks, at which it heard, in addition to the four experts who had testified at trial in 2001-2002, from an additional thirteen experts-eight for the defense and five for the prosecution. ${ }^{109}$ At the conclusion of those proceedings, the court granted a new trial, finding that "the credible evidence adduced at the Hearing, which was supported by expert testimony from different disciplines and specialties-pediatrics, radiology, pathology, ophthalmology, and biomechanical engineering established by a preponderance of the evidence that key medical propositions relied upon by the Prosecution at Trial were either demonstrably wrong, or are now subject to new debate." ${ }^{110}$ The trial court's decision was affirmed on appeal. ${ }^{111}$

Among the more dramatic of such cases was the holding of a federal judge in the Northern District of Illinois in 2014. After hearing from multiple experts, the court held that Jennifer Del Prete had proved her actual innocence in an SBS case sufficiently to permit her to proceed in federal habeas corpus despite having procedurally defaulted her constitutional claims in state court. ${ }^{112}$ In addition to finding-based on consideration of the extensive expert testimony presented-that Del

(Barnes) was one of the experts who testified on behalf of Edmunds in the postconviction proceedings.

107. Id. at 593.

108. Id. at 596.

109. See People v. Bailey, 999 N.Y.S.2d 713, 715-22 (2014). Full disclosure: One of us (Findley) was co-counsel for the defendant, Rene Bailey, in that case, and two of us (Barnes and Mack) were expert witnesses for the defense in the postconviction proceedings.

110. Id. at 726 .

111. People v. Bailey, 144 A.D.3d 1562 (N.Y. App. Div. 2016).

112. Del Prete v. Thompson, 10 F. Supp. 3d 907 (N.D. Ill. 2014). Full disclosure: One of us (Barnes) testified as an expert witness for the defense in this case, and another (Mack) consulted with experts for the defense but did not testify. 
Prete was probably innocent of the SBS offense, the court added in a footnote that "the . . . recent [scientific] developments in this area . . . arguably suggest[] that a claim of shaken baby syndrome is more an article of faith than a proposition of science." 113

Just as this article was going to print, the en banc Court of Appeals of the State of Mississippi issued a decision holding that it was error to admit the opinion of a pediatrician purporting to "diagnose" SBS. In the course of its ruling, the Court observed that the record included "evidence that showed the reliability of SBS as a diagnosis is being increasingly challenged and questioned . . . ." 114 The court also observed that the prosecution's pediatrician "agreed that many articles in many different disciplines, from neuropathology to biomechanical engineering, discount SBS as a reliable diagnosis." 115 Further, the court noted that it had been presented with "numerous cites to studies and peer-reviewed articles, that reflected the scientific community may no longer wholly accept SBS." 116

In sum, despite the SPR's claim of "consensus," the reliability of SBS/AHT diagnoses is very much a matter of serious and widespread controversy, in both medical and legal fora.

\section{IS AHT A “MEDICAL DIAGNOSIS” OR A “LEGAL CONCLUSION”?}

\section{A. The SPR's Claims}

The SPR emphatically proclaims that the AHT conclusion "is a medical conclusion, not a legal determination . . . "117 The significance of this claim is two-fold. First, it supposedly justifies permitting physicians to render opinions about the etiology of a child's brain injuries based on determinations that are often made by multidisciplinary child-abuse-prevention teams that include not only physicians, but also social workers, police officers, and prosecutors. ${ }^{118}$

113. Id. at 957-58 n. 10 .

114. Clark v. State, 2017-KA-00411-COA, 2019 WL 5566234, ๆ 33 (Miss. Ct. App. Oct. 29, 2019).

115. Id. ๆ 41.

116. Id. 47.

117. Choudhary et al., supra note 10, at 1049.

118. See, e.g., U.S. DeP't of Justice, Office of Justice Programs, Office of Juvenile Justice and Delinquency Prevention, Forming a Multidisciplinary Team to Investigate Child Abuse 5-6 (Nov. 1998) ("In many States, the membership of MDT's [Multi-Disciplinary Teams] is defined by statute. Generally, laws authorizing or requiring the formation of investigative MDT's specify that law enforcement, child protection or family services, and prosecution participate. Even if your State does not require such membership, these three disciplines and the medical professions should be considered the core of any investigative MDT."). 
The resulting determinations are often made on the basis of facts well beyond the presenting medical conditions, such as caregiver demeanor or perceived inconsistencies in the caregiver's narrative of events. ${ }^{119}$ Second, it lays the groundwork for telling lawyers and courts that they cannot second-guess the physicians and must defer to their judgment on whether a child has been abused. Together, these factors then justify permitting the physician to go beyond what other witnesses are permitted to do-to render opinions, and not just testimony based on personal knowledge, under Fed. R. Evid. 703 and Daubert ${ }^{120}$ or Frye, ${ }^{121}$ depending on the jurisdiction.

Hence, the SPR proclaims that " $[\mathrm{t}]$ he diagnosis of AHT is a medical diagnosis made by a multidisciplinary team of pediatricians and pediatric subspecialty physicians, social workers and other professionals based on consideration of all the facts and evidence." 122 The "other professionals" mentioned in this sentence are typically police and prosecutors, although the SPR statement chooses not to make that explicit. The SPR elaborates that "[a] diagnosis of AHT is a medical conclusion, not a legal determination of the intent of the perpetrator or, in the false hyperbole of the courtroom and sensationalistic media, 'a diagnosis of murder." 123 Later, the SPR devotes an entire subsection to the topic under the heading, "AHT is a medical diagnosis not a legal finding of murder." 124

The SPR statement's argument for this claim is that " $[\mathrm{t}] \mathrm{he}$ medical expert in a child abuse case plays just one role-to help the judge or jury answer the medical question of whether an infant's injuries were most likely caused by abuse or they could be plausibly explained by a recognized disease or by one or more of the myriad hypothetical alternative causal explanations typically proffered by the defense." 125 The statement reasons:

It is absurd to argue that a medical diagnosis proves murder. Medical expert testimony on the etiology of the injury cannot answer the two foundational legal questions of actus reus (Latin for guilty act) or mens rea (Latin for guilty mind). That is because, even after the factfinder decides that the medical evidence supports a finding that an infant's injuries were inflicted, non-medical evidence is required to determine who

119. See id. at 4-6, 11 .

120. Daubert v. Merrell Dow Pharm., Inc., 509 U.S. 579 (1993).

121. Frye v. United States, 293 F. 1013 (D.C. Cir. 1923).

122. Choudhary et al., supra note 10, at 1049 (emphasis added).

123. Id. (emphasis added).

124. Id. at 1059 (emphasis added).

125. Id. (emphasis in original). 
committed the act and to determine the level of intent (e.g., knowing, reckless or negligent). ${ }^{126}$

The statement elaborates:

To cite an analogous example that disproves the argument's premise, the toxicologist who testifies that the victim was poisoned does not diagnose murder because the court must still decide the actus reus (how was the poison ingested?) and the mens rea (was the victim's poisoning accidental, negligent, reckless or intentional?). ${ }^{127}$

\section{B. Foundational Question-Is the Conclusion of SBS/AHT Even a "Diagnosis" as that Term is Used in Medicine?}

Before addressing the claim that the SBS/AHT conclusion is not in any way a legal matter, we note that the SPR's claims present a foundational question-is the abuse determination a medical "diagnosis"? The SPR certainly claims as much, but the use of the term "diagnosis" is wrong, for these cases do not involve a medical diagnosis in the true sense. ${ }^{128}$ Rather, they involve a causation inquiry that goes beyond diagnosis, and ventures into etiology - a matter that in most contexts, including these, exceeds the training and expertise of clinical physicians. ${ }^{129}$ As generally used in medicine, diagnosis refers to the process of determining the disease or dysfunctional condition from which a patient suffers in order to determine the best course of

126. Id. (emphasis in original).

127. Id. (emphasis in original).

128. Note that, even if AHT/SBS were truly a medical diagnosis, at least according to physicians, that would not resolve the problem with opinion evidence in court on those matters. The Rules of Evidence, and not the role-inflating claims of some physicians themselves, determine the scope of admissible expert opinion evidence. That the determination of abuse is not a true medical diagnosis merely adds at a foundational level to the problems with the expert opinion evidence being propounded by child abuse physicians in SBS/AHT cases. We take up this matter in the next section of this Article.

129. The authors of the "consensus" piece characterize AHT as a "diagnosis" thirty-seven times but recognize its fundamental nature as an etiology seven times in their text. Choudhary et al., supra note 10, at 1048-52, 1054-55, 1057-60. Consider this, from their abstract: "A multidisciplinary team bases this diagnosis on history, physical examination, imaging and laboratory findings. Because the etiology of the injury is multifactorial (shaking, shaking and impact, impact, etc.) the current best and inclusive term is AHT." Id. at 1049.

This is an interesting ploy, using what is essentially word magic to capture the benefits of the diagnostic function as a presumptive part of medical training and expertise, but at the same time asserting that etiological inference (or conjecture) without benefit of empirical research is a legitimate part of "diagnosis." 
treatment to cure or relieve the disease or condition. ${ }^{130}$ The disease or condition is inferred from signs, symptoms, risk factors, and the results of diagnostic tests. Signs are objective conditions or manifestations observed by the physician either directly or with the aid of senseenhancing instruments such as a stethoscope. Symptoms are subjective reports of pain, weakness, or other conditions associated with the complaint of the patient in regard to a dysfunctional condition or disease. Risk factors (beyond those represented directly by signs or symptoms) are such things as family history of disease, exposure to disease-causing agents, etc., which are usually derived from the patient's history as recounted by the patient (or next of kin), or derived from the patient's previous medical records. To be appropriately considered in diagnosis, risk factors must have been established as being such by previous empirical research. ${ }^{131}$ Finally, diagnostic tests, which are often the result of microscopic or chemical analysis of bodily fluids or tissues or microorganism cultures derived from the body of the patient, give results correlated by previous research with certain diseases or conditions. They are usually performed by someone other than the treating physician and are often now instrumented to a greater or lesser degree.

One thing to note at the outset is that diagnosis is not directly concerned with the cause of a disease or condition, although some diagnoses will entail causes established by previous research, and some diagnostic tests will reveal the presence of a causal agent associated with the condition by previous research. The point is that diagnostic judgment itself does not address causation independent of previous research on the cause of a disease or constellation of signs and symptoms. ${ }^{132}$

Here we must be clear on the sense in which we are using the term "cause." It is not uncommon to say that when a particular disease has been identified as the source of a person's signs and symptoms, the diagnosis has identified the "cause" of those signs and symptoms. In a non-technical and extended sense this is not incorrect, but not in the sense covered by the concept of etiology, which deals with the question of what original conditions cause the disease itself. Malaria provides a helpful example. ${ }^{133}$ For centuries malaria was easily diagnosed in

130. Findley \& Risinger, supra note 64, at 1219.

131. Id.

132. See Anthony G. Hopp, Jeremy S. Goldkind \& David M. Cummings, Differential Diagnosis and Daubert: Preventing the Misuse of Differential Etiology to Prove Causation in Toxic Tort Cases, 84 DEF. Couns. J. 1, 6 (2017).

133. Many other such stories from the great age of the identification of infectious microorganisms that were the cause of well-known diseases could be set out here, such as cholera, tuberculosis, etc. See Malaria, WIKIPEDIA.COM, https://en.wikipedia.org/wiki/Malaria [https://perma.cc/6FYQ-XLPM]. 
typical cases involving malarial paroxysm-shaking chills alternating with high fever and sweats over a two- or three-day cycle. However, the cause, in any useful sense, was unknown (the very name indicates the cause was assigned to "bad air.") Identifying the cause of malaria in detail is a triumph of modern medical research, beginning in 1880 with Laveran's observation of parasites in the blood of infected individuals, and continuing in the subsequent decades as the different species of Plasmodium responsible for the variations of the disease, and the role of mosquitos in spreading the infection was worked out in detail. ${ }^{134}$ So a physician in 1875 could diagnose the disease, and even treat some cases fairly well with quinine, but had no well-warranted idea of the cause of the disease itself-its etiology.

Pneumonia provides another useful example. The symptoms and signs of pneumonia can include cough, shortness of breath, fever and abnormal lung sounds. A clinician may order diagnostic tests including bloodwork, culture, X-ray or sometimes a CT exam. The diagnosis is based on all of these clinical signs and symptoms as well as diagnostic testing. But the particular etiology of that pneumonia need not be identified to treat the patient (and few physicians would claim to be able to "diagnose" how a particular pneumonia developed in any one patient). Regardless of cause, the treatment would be for the illnesstypically a broad-spectrum antibiotic. And that is as far as the causation inquiry would go; the physician would not venture into "diagnosing" how or what introduced that organism into the body. Child abuse physicians, by contrast, take that one extra step-by analogy to the pneumonia case, they assume they know how the patient acquired the pneumonia.

The iterative process known as differential diagnosis also is not designed to address etiology. "Differential diagnosis refers to the process whereby the physician ideally determines a wide range of diseases or conditions that might account for a set of signs and symptoms, rank orders them by probability (or sometimes severity), and proceeds to attempt to rule out the members of the list by further tests." 135

In practice, whether one actually rules out of every possibility except one will depend on the remoteness of initial probabilities and the availability and expense of diagnostic tests . . . [O]ften the most life-threatening or the most probable disease after convenient diagnostic testing has been done will be treated first . . . [O]nly when treatment fails will that disease be eliminated and either further more rigorous or

134. Id. See the history section of the Wikipedia article on malaria.

135. Findley \& Risinger, supra note 64, at 1220. 
costly testing, or treatment for the next most likely disease, be undertaken. Note that differential diagnosis involves a feedback loop where initial diagnostic hypotheses are modified in light of newly acquired information. And most importantly, skill in differential diagnosis (or diagnosis generally) does not provide one with special skill in determining causation in regard to the disease or condition finally settled on and treated successfully. The skill is in determining the disease or condition in the patient, and knowing how to treat it successfully, not in determining its cause. Determining cause (the "etiology" of a disease) is a specialty of scientific medical research, not of practical diagnosis by practicing physicians. ${ }^{136}$

Of course, once such etiology has been established by welldesigned medical research, it may become a part of the process of diagnosis. This applies both to the testing for known pathogens as part of diagnosis (illustrated above in the pneumonia example), as well as discovering exposure to previously established risk factors.

Of course, practicing physicians may be willing to opine on the causation of conditions like various cancers that have not yet been established by research, and they may invoke their diagnostic skills in the process, but this is misplaced; determining the etiology of a disease that has not yet been established by formal research is beyond the scope of the practitioner's training and expertise and represents no more than a conjectural hypothesis at best. ${ }^{137}$ There is no training, formal or otherwise, in the practice of "differential etiology" in medical school.

136. Id. (footnote omitted).

137. Id. at 1220-21. As the United States Court of Appeals for the Fifth Circuit explained in the course of holding that it was error to permit a physician to opine that a specific slip-and-fall accident was the cause of the plaintiff's fibromyalgia (a nonspecific, chronic-pain illness):

The court's task was to determine whether Dr. Reyna's methodology tied the fall at Food Lion by some specific train of medical evidence to Black's development of fibromyalgia. No one doubts the utility of medical histories in general or the process by which doctors rule out some known causes of disease in order to finalize a diagnosis. But such general rules must, under Daubert, Kumho Tire, and Moore, be applied fact-specifically in each case. The underlying predicates of any cause-and-effect medical testimony are that medical science understands the physiological process by which a particular disease or syndrome develops and knows what factors cause the process to occur. . . . In this case, neither Dr. Reyna nor medical science knows the exact process that results in fibromyalgia or the factors that trigger the process. Absent these critical scientific predicates, . . . no scientifically reliable conclusion on causation can be drawn. 
Indeed, in civil cases, courts have recognized the important distinction between differential etiology and differential diagnosis, and that the former is a much more dubious proposition. ${ }^{138}$ The difference is significant. ${ }^{139}$ The differential diagnosis, as a rule, "does not provide an adequate basis for establishing external causation." ${ }^{140}$ Rather, the differential diagnosis "focus[es] on diagnosing the disease, not on determining the etiology or cause of the disease." 141 "[D]ifferential etiology," by contrast, "describe[s] the investigation and reasoning that leads to the determination of external causation, sometimes more specifically described by the witness or court as a process of identifying external causes by a process of elimination." ${ }^{142}$ As one civil court put it bluntly, "[t]he differential diagnosis method has an inherent reliability; the differential etiology method does not." 143

To understand why, consider Bowers v. Norfolk S. Corp. ${ }^{144}$ The case was a tort action by a railroad employee against his employer, seeking damages for injuries he claimed he sustained from the vibrations of the train on which he worked. ${ }^{145}$ The court held that the differential diagnosis could be used to determine the nature of the plaintiff's medical condition. But determining that the locomotive's vibrations were the cause-in-fact of those injuries was another matter, beyond the scope of the differential diagnosis and the physician's expertise. ${ }^{146}$ The court noted that, when diagnosing a patient for treatment purposes, the doctor has special incentives that provide

Black v. Food Lion, 171 F.3d 308, 314 (5th Cir. 1999). It is widely recognized that the pathophysiology of SBS/AHT, like the pathophysiology of fibromyalgia, is not well understood. See supra notes 27 and 40 and accompanying text.

138. See, e.g., Bowers v. Norfolk S. Corp., 537 F. Supp. 2d 1343, 1360-61 (M.D. Ga. 2007), aff'd, 300 F. App'x 700 (11th Cir. 2008); Hendrix ex rel. v. Evenflo Co., Inc., 609 F.3d 1183 (11th Cir. 2010); C.W. ex rel. Wood v. Textron, Inc., 807 F.3d 827 (7th Cir. 2015); Tamraz v. Lincoln Elec. Co., 620 F.3d 665, 673 (6th Cir. 2010); Higgins v. Koch Dev. Corp., 794 F.3d 697, 705 (7th Cir. 2015); Myers v. Illinois Central R.R., 629 F.3d 639, 644 (7th Cir. 2010); see also TUERKHEIMER, supra note 46 , at 75 .

139. The discussion of this issue that follows is adapted from Keith A. Findley, Flawed Science and the New Wave of Innocents, in Wrongful ConviCTIONS AND THE DNA REVOLUTION 184, 190-93 (Daniel S. Medwed, ed. 2017).

140. TUERKHEIMER, supra note 46, at 76; see also Hopp, supra note 127 , at 6 .

141. Id.

142. McClain v. Metabolife Int'l, Inc., 401 F.3d 1233, 1252 (11th Cir. 2005) (quoting Mary Sue Henifin, et al., Reference Guide on Medical Testimony, in Reference Manual on Scientific Evidence 439, 481 (Federal Judicial Center 2d ed., 2000)).

143. Bowers, 537 F. Supp. 2d at 1361; see also TUERKHEIMER, supra note 46, at 76; Findley, supra note 139, at 191.

144. Bowers, 537 F. Supp. 2d at 1343.

145. Id. at $1344-45$.

146. Id. at 1362 . 
assurances of accuracy: misdiagnosis can lead to catastrophic illness for the patient, even death, from failure to prescribe the correct treatment. ${ }^{147}$ And that error can in turn lead to medical malpractice liability. ${ }^{148}$ When a physician opines that a train worker's physical injuries were caused specifically by the train's vibrations, or that a child's brain injuries were caused by abuse, however, she is not diagnosing the patient for treatment purposes. In the SBS/AHT case, the diagnosis is brain injury, and it is that injury that is treated. Whether an injury was inflicted or sustained accidentally has no bearing on the way a patient is treated medically.

This reality has other implications undermining the reliability of the differential etiology. The true differential diagnosis-diagnosing a patient's medical illness or condition for purposes of prescribing treatment-at least has the potential for enabling the doctor to learn from experience, and thus improves reliability. If the doctor misdiagnoses an illness or condition, the treatment will likely fail, and the doctor will adjust the diagnosis and the treatment accordingly. But because there is no similar treatment feedback loop to differentiate between abusive and non-abusive injuries, judgments about causation (etiology) do not offer similar opportunities for learning and for ensuring experience-based reliability.

Medical professionals have recognized this challenge even in the context of true diagnosis. Eta Berner and Mark Graber, for example, have observed that, where feedback is absent or minimal, overconfidence by the physician can be a significant source of diagnostic error: "[F]eedback that is delayed or absent may not be recognized for what it is, and the perception that 'misdiagnosis is not a big problem' remains unchallenged. That is, in the absence of information that the diagnosis is wrong, it is assumed to be correct . . . ." 149 And Gordon Schiff has explained how the absence of feedback can undermine reliability, even in the true diagnosis context:

An open-loop system (also called a "nonfeedback controlled" system) is one that makes decisions based solely on preprogrammed criteria and the preexisting model of the system. This approach does not use feedback to calibrate its

147. Id. at 1361 .

148. Id.

149. Eta S. Berner \& Mark L. Graber, Overconfidence as a Cause of Diagnostic Error in Medicine, 121 AM. J. MED. S2, S10 (2008). 
output or determine if the desired goal is achieved. . . . [Such a system] cannot engage in learning. ${ }^{150}$

Because opining about the etiology of a child's brain findings provides no feedback mechanism, the entire enterprise is untethered from empirical confirmation. Without the feedback required to "engage in learning," the expert's opinions based on clinical judgment can amount to little more than ipse dixit, which the Supreme Court has recognized as problematic under the Federal Rules of Evidence. ${ }^{151}$

As problematic as the causation determination can be in tort cases, that determination, employing a differential etiology methodology, is even more challenging in SBS/AHT cases. The reason is simple. In the typical tort case, the question posed to the expert is whether a known historical fact connects causally to a known injury or outcome. But in SBS/AHT cases, the historical fact at issue-whether the accused violently shook or shook and slammed the child-is itself unproven and unknown. In the SBS/AHT context, the expert is asked to relate cause to effect when only the effect has been observed; it asks the expert to divine not only the relationship between the precipitating event and the outcome, but to divine even the existence of the alleged precipitating event itself, which has not been observed or otherwise proven.

In the Bowers scenario, for example, the train engineer in fact suffered the injuries of which he complained, and he was in fact exposed to the vibrations that he claimed caused those injuries. Similarly, in a toxic tort case, typically there is no dispute that the plaintiff in fact contracted cancer, or was born with birth defects, and that the plaintiff was in fact exposed to the toxins or carcinogens. The question for the expert in either scenario is whether the known exposure caused the known outcome. Nonetheless, that is the type of causation claim that Douglas Weed observes is so difficult to make, because it "does not have [the] sort of connection back to some unique event that can be documented, verified, and directly observed." 152

But in SBS/AHT cases, the expert's opinion is needed precisely because the existence of the act of shaking or abusing the child is otherwise not established. The children in such cases cannot describe what happened, because they are either pre-verbal or deceased (or both). The medical expert must not only infer that shaking caused the

150. Gordon D. Schiff, Minimizing Diagnostic Error: The Importance of Follow-up and Feedback, 121 AM. J. MED. S38, S38 (2008).

151. See Gen. Elec. Co. v. Joiner, 522 U.S. 136, 146 (1997) ("But nothing in either Daubert or the Federal Rules of Evidence requires a district court to admit opinion evidence that is connected to existing data only by the ipse dixit of the expert.").

152. Douglas L. Weed, Truth, Epidemiology, and General Causation, 73 BRoOK. L. REV. 943, 949 (2008). 
child's injuries, but that the shaking even occurred in the first instance. As a category of cases, therefore, SBS/AHT cases present in stark form the tensions that lie at the interface between law and science.

In other words, at least in civil cases the clinical practitioner's musings about etiology generally concern hypotheses about causal mechanisms that, however much they have not been tested empirically, at least could in theory be tested empirically. The "abuse" conclusion entailed in AHT testimony involves conclusions about subjective mental states that are not subject to the protocols of medical research even in theory. In regard to such mental states, which are what define criminal responsibility legally, physicians and medical researchers are in no better position to make inferences from the factual circumstances surrounding a death than are ordinary human beings applying critical common sense. Such issues are reserved for the jury without opinions being offered by putative experts whose opinions are beyond the scope of their expertise, and invite inappropriate deference by jurors. ${ }^{153}$

An instructive case dealing with what is essentially the same issue in the testimony offered by a forensic pathologist is State v. Tyler, ${ }^{154}$ a case decided by the Supreme Court of Iowa involving the sudden unexplained death of an infant. In that case the trial court had permitted the Medical Examiner to testify to his conclusion that the "manner of death" was homicide. ${ }^{155}$ The Iowa high court held that this was error because the conclusion was not a medical opinion based on specialized knowledge; it was instead a non-expert opinion based mostly on information derived from law enforcement investigators-information that the Medical Examiner's medical expertise did not enable him to evaluate more reliably than the jury. ${ }^{156}$ As there, so here.

Because the nature of the conclusions offered by physicians in court under the label Abusive Head Trauma do not involve diagnosis, and are in part conclusions about subjective mental states beyond the scope of medical etiology, we have generally referred to them in this paper simply as "AHT conclusions or determinations," except where direct quotation or context necessitates the use of the term "diagnosis."

153. Judges often refer to such opinions variously as "invading the province of the jury," "outside the scope of the witnesses' expertise and specialized knowledge," "not beyond the ken of the average juror," "not helpful to the jury," and other such phrases. See, e.g., Kimble v. Earle M. Jorgenson Co., 830 N.E.2d 814, 823 (2005); Lee v. Andersen, 616 F.3d 803, 808-09 (8th Cir. 2010); Daubert v. Merrell Dow Pharm., Inc., 509 U.S. 579 (1993).

154. 867 N.W.2d 136 (Iowa 2015).

155. Id. at $145-47$.

156. Id. at $163-64$. 


\section{The Legal Essence of the "Diagnosis"}

By invoking "diagnosis," the "consensus" document is using what is essentially word magic to capture the benefits of the diagnostic function as a presumptive part of medical training and expertise, but at the same time asserting that etiological inference (or conjecture) without benefit of empirical research is a legitimate part of "diagnosis." But putting aside whether the definition of "diagnosis" can be stretched in some extended sense to cover AHT conclusions, it remains the case that most of the core AHT conclusions constitute legal characterizations and not objective scientific facts. Despite the SPR's claims that the SBS/AHT conclusion says nothing about legal matters like actus reus and mens rea or identity of the purported abuser, the very term "abusive head trauma," or its alternative formulations in the medical literature, such as "non-accidental head injury" (NAHI), "inflicted traumatic brain injury" (ITBI), and the like, do precisely what the SPR says they do not do. To opine that the abuse was "inflicted"-whether by violent shaking or impacting the child's head, or both, which are the inferred mechanisms of injury in AHT-adds nothing but the legal requirements of actus reus, mens rea, and even (albeit somewhat less directly) identity.

First, to label the etiology as "inflicted" or "abusive" or "nonaccidental" serves precisely to opine as to the actus reus, the guilty act. The medical opinion purports to tell us precisely that which the law requires-what action did the accused take? While the medical hypothesis no longer claims to be able to specify whether the mechanism of injury was shaking or impact or both (hence the shift in the nomenclature from SBS to the more-inclusive AHT), it tells us all that the law requires to satisfy the actus reus requirement-that someone applied violent force to harm the child. ${ }^{157}$

Second, the term "abusive head trauma" or any of its formulations also by their very nature satisfy the mens rea element of the crime of child abuse (or its variants). Child abuse statutes set the requisite mental state for criminal conduct at various levels, from intentional to reckless to negligent or knowing. Purely blameless accidental conduct is never criminal. The SPR statement contends that when a physician opines that "an infant's injuries were inflicted," he or she is not offering evidence about or diagnosing the mental state needed to

157. In this regard, a very recent decision of the Georgia Supreme Court in an abusive head trauma case is telling. In that case, the court observed that "the case against the [defendants] was entirely circumstantial, and the only evidence that a crime had been committed at all was the expert medical testimony of Dr. Darrisaw, the State's medical expert who performed the autopsy." Debelbot v. State, 826 S.E.2d 129, 134 (Ga. 2019) (emphasis added). 
establish a crime. ${ }^{158}$ But then what exactly are the conclusions that the injuries were "inflicted" and were "abusive" doing? Their only purpose, in addition to establishing the actus reus, is to prove the mental state of the alleged abuser; they serve no other purpose, medical or otherwise. These are quintessentially legal questions, not medical questions, ${ }^{159}$ they have no medical implications at all, since there is no difference in treatment for the brain injuries a child suffers depending on whether any trauma the child suffered was applied intentionally (inflicted) or accidentally. But this does answer the mens rea question: if the injury is inflicted or the result of abuse, then the caregiver acted not accidentally, but with a guilty mind. And the only consequences of this determination are solely legal: if the injury is inflicted, the child might be removed from the parents, or the caregivers might be prosecuted criminally.

Elsewhere, the child abuse literature written by strong proponents of the SBS/AHT hypothesis confirms that doctors, including child abuse pediatricians, realize how the "diagnosis" resolves legal questions. Indeed, previously the SPR's own ad hoc Committee on Child Abuse, in 2005, acknowledged in writing that "[t]he testimony of pediatric radiologists can be crucial in the differentiation of child abuse from accidental fractures, metabolic diseases, and other bone disorders. In cases where child abuse is suspected, a physician's opinion will often be determinative." 160 Likewise, child abuse pediatrician John Leventhal at Yale notes that, when evaluating a child for suspected abuse, the physician must consider what he calls "[t]wo important questions": "First, are the child's findings due to trauma or a medical problem (or a combination of the two)? Second, if trauma, are the injuries due to abuse as opposed to neglect, an unintentional (or accidental) cause or birth trauma?"

158. Choudhary et al., supra note 10, at 1059.

159. In this regard, the observations of a team of medical and scientific experts appointed by the Swedish government to investigate the scientific foundations for the SBS hypothesis are apt:

The term [SBS], however, is problematic as it includes both the medical findings and the alleged, but scientifically unproven, injurious mechanismand even the intent behind this mechanism.

Hence, we ought to differ between the injurious mechanism (traumatic shaking) and the medical findings (the symptoms and signs, "the triad"). Intent is not, for obvious reasons, for the medical community to decide.

Niels Lynøe, Niklas Juth, \& Anders Eriksson, From Child Protection to Paradigm Protection-The Genesis, Development, and Defense of a Scientific Paradigm, J. MED. \& PHIL. 378, 379 (2019) (emphasis in original).

160. Kenneth L. Mendelson, Critical Review of "Temporary Brittle Bone Disease, ” 35 PEdiatric Radiology 1036, 1036 (2005).

161. See Leventhal et al., supra note 50, at S537 (emphasis added). 
Finally, it is misleading, at best, to suggest that the medical opinion does not address identity; in the typical case, the medical opinion provides all the prosecutor needs to prove identity of the perpetrator. As the SPR statement itself asserts, most prosecution experts reject the notion that a child so injured would have any extended period of lucidity after injury. ${ }^{162}$ Hence, the medical opinion purports to establish that the person with the child at or very near the time of collapse or onset of major symptoms must have been the one who harmed the child. ${ }^{163}$ In this regard, Dr. Leventhal's writings again reveal that the "diagnosis" is ultimately a conclusion about a legal question. Leventhal highlights the importance of timing the child's injuries, observing, "[a]n understanding of the timing of the injury can help answer the question of who hurt the child, which, in turn, affects whether an alleged perpetrator will be arrested and prosecuted."164

162. Choudhary et al., supra note 10, at 1052 ("There is no evidence that children with fatal head trauma have prolonged asymptomatic lucid intervals prior to neurologic collapse."). This assertion, however, is misleading at best, and flat-out wrong at worst. There is in fact considerable evidence in the literature that children with fatal brain injuries can have prolonged periods of lucidity prior to collapse, ranging from minutes to hours or even days. See M.G.F. Gilliland, Interval Duration Between Injury and Severe Symptoms in Nonaccidental Head Trauma in Infants and Young Children, 43 J. ForENSIC SCI. 723 (1998) (reporting extensive lucid intervals in some cases, including some of more than seventy-two hours); Robert W. Huntington, III, Symptoms Following Head Injury, 23 Am. J. ForensiC Med. \& Pathology 105 (2002) (reporting on a case in which an apparently abused thirteen-month-old child was admitted to the hospital and was under professional medical care and supervision for less than twenty-four hours before she collapsed and died, at which time physicians for the first time discovered severe intracranial injury, with subdural hemorrhage, retinal hemorrhage, and cerebral edema); Scott Denton \& Darinka Mileusnic, Delayed Sudden Death in an Infant Following an Accidental Fall, 24 AMER. J. ForensiC MED. \& PATHOLOGY 371 (2003) (case report of a nine-month-old child who experienced a seventy-two hour lucid interval). While it is true that the children in these circumstances usually are not wholly symptom-free, the symptoms can be subtle and difficult to discern in pre-verbal infants and toddlers-symptoms like clinginess, fussiness, vomiting, interrupted sleep or eating patterns, and the like. See Huntington, supra (explaining that physicians did not recognize the child's severe intracranial injuries initially because she was "fussy and clingy, but interactive and responsive"); Gilliland, supra, at 724 (noting that during the periods of lucidity the children were described as "not normal"). Children are not always immediately comatose or unresponsive, as child abuse pediatricians have typically claimed in the past.

163. For discussion of the use of the no-lucid-intervals claim to prove identity, see Deborah Tuerkheimer, The Next Innocence Project: Shaken Baby Syndrome and the Criminal Courts, 87 WASH. U. L. REV. 1, 5, 18 (2011) (noting "[u]nequivocal testimony regarding timing-i.e., that symptoms necessarily would appear instantaneously upon the infliction of injury-proves the perpetrator's identity"); Findley et al., supra note 3, at 225-26 (noting testimony claiming "there could be no period of relative normality ('lucid interval') following the injury. It was therefore widely accepted that the last person with the baby must have been responsible." (footnote omitted)).

164. Leventhal et al., supra note 50, at S537 (emphasis added). 
Leventhal reiterates that "[i]t is useful to know who was present when the child became symptomatic, especially if the symptoms occurred rapidly and during a short period of time. This information can help determine who may have hurt the child . . . ."165

A recent decision from an Ohio appellate court exemplifies this problem with-and the all-encompassing nature of-the "medical diagnosis" of SBS/AHT. In reversing the accused's conviction as being against the manifest weight of the evidence, the court observed that the prosecution's child abuse pediatrician, Dr. Randall Schlievert, "examined E.A. on the night of the incident, and concluded not only that E.A. had suffered shaken baby syndrome, but that appellant was the perpetrator. Upon Schlievert's conclusion, all criminal investigation into the cause of E.A.'s injuries stopped."166

Insight on this is further gleaned from the writings of Dr. Norman Guthkelch, one of the physicians credited with originating the SBS hypothesis in a paper written in 1971, although he did not call it that at the time. ${ }^{167}$ More than forty years later, reflecting on what had happened to his hypothesis in the intervening years, Dr. Guthkelch lamented that the claim to "diagnose" SBS and AHT reflects overreaching by the medical community:

Since subdural and retinal hemorrhages (with or without cerebral edema) may also be observed in accidental or natural settings, I suggest that the elements of the classic triad of retinal hemorrhage, subdural hemorrhage and cerebral edema would be better defined in terms of their medical features. Since subdural hemorrhages in infancy originate in the dura, perhaps "retino-dural hemorrhage of infancy" would be an acceptable name for the primary findings. Other medical findings, e.g., cerebral edema, can be added to the title as appropriate. This would allow us to investigate causation without appearing to assume that we already know the answer. ${ }^{168}$

Dr. Guthkelch further observed: "Tuerkheimer has pointed out the danger of assuming criminal intent simply because the classic triad of retino-dural hemorrhage and encephalopathy is present and no one can

165. Id. at $\mathrm{S} 538$

166. State v. Thoss, 120 N.E.3d 1274, 1283 (Ohio Ct. App. 2018).

167. See A.N. Guthkelch, Infantile Subdural Haematoma and Its Relationship to Whiplash Injuries, 2 BRIT. MED. J. 430 (1971).

168. Guthkelch, supra note 28, at 202 (emphasis added). 
think of any other explanation." 169 Accordingly, Dr. Guthkelch concluded, "[a]ny medical expert who answers in the negative questions such as 'Given the injuries that you have described in this case, doctor, have you any doubt that they were inflicted with intent to kill, or at least in total disregard of that possibility?' is exceeding his or her authority." 170

If any question remains about the legal nature of the purported diagnosis, one need only look to the actual courtroom testimony of medical experts who testify on behalf of the prosecution in criminal and family cases. Routinely, these witnesses testify, for example, that the forces required to cause the injuries suffered by the child at issue had to have been so massive they could not have been accidental, often likened to the forces of an automobile accident at thirty miles per hour or more, or throwing a child from a multi-story building. ${ }^{171}$ (Indeed, a chapter by a prosecutor in a child-abuse textbook urged that physicians "can testify that the forces the child experiences [from shaking] are the equivalent

169. Id. at 203 (citing Deborah Tuerkheimer, Science-Dependent Prosecution and the Problem of Epistemic Contingency: A Study of Shaken Baby Syndrome, 3 Ala. L. REV. 523 (2011)).

170. Guthkelch, supra note 28, at 204.

171. See, e.g., Imwinkelried, supra note 64 and cases cited therein (noting that "[t]he most common analogies [used by prosecution experts] are to the amount [of force] generated by high speed automobile accidents and a fall from a several-story building). The experts analogize to these 'real-life accident scenarios' in order to give the trier of fact a sense of the 'massive, violent' force required to produce this kind of brain injury." Cited cases include Mitchell v. State, No. CACR 07-472, 2008 WL 316166 , at $* 2$ (Ark. Ct. App. Feb. 6, 2008) (examining pediatrician equated the force necessary to produce the triad with that of a high-speed automobile accident); People $v$. Dunaway, 88 P.3d 619, 631, 631-32 (Colo. 2004) (explaining how the prosecution expert stated that subdural hematomas occur in "such things as falling from a several story building or being in a high speed motorcycle accident or a child say is on a bicycle hit by a car . . . . [W] hen we see subdurals in accidental injury, it's from a major trauma. It requires massive force"); In re Matter of Child, 880 N.Y.S. 2d 760, 765 (N.Y. Fam. Ct. 2008) (explaining how the prosecution expert stated that SBS findings "simulate being in a car crash at 'around [thirty-five] to [forty] miles per hour'”). See also Transcript of Testimony of Dr. Gregory Hollman at 78, State v. Edmunds, No. 96-CF-555 (Dane Cty. Cir. Ct. Nov. 21, 1996) (explaining that the forces required from shaking "would be [the equivalent of throwing a child from] right around a three story building, three to four story building"). See also Papetti et al., supra note 24, at $311 \mathrm{n} .60$ (collecting other cases in which physicians testified similarly). That testimony is also consistent with claims in the published medical literature of the early 2000s. See, e.g., Case et al., supra note 23, at 120 ("Fatal accidental shearing or diffuse brain injuries require such extremes of rotational force that they occur only in obvious incidents such as motor vehicle accidents. . . . [Or from] falling from considerable heights (greater than [ten] feet) or having some object penetrate the head."); Am. Acad. of Pediatrics, Comm. on Child Abuse \& Neglect, Shaken Baby Syndrome: Rotational Cranial Injuries-Technical Report, 108 PEDIATRICS 206, 206 (2001) (position paper of the American Academy of Pediatrics proclaiming that " $[\mathrm{t}]$ he act of shaking is so violent that individuals observing it would recognize it as dangerous and likely to kill the child"). 
of a fifty to sixty miles per hour unrestrained motor vehicle accident, or a fall from three to four stories onto a hard surface." ${ }^{172}$ ) Routinely, therefore, child abuse physicians testify that anyone applying or observing those forces would have recognized that they would cause severe harm to the child. ${ }^{173}$ The 1993 position paper of the American Academy of Pediatrics (AAP) even explicitly instructed pediatricians that "the act of shaking/slamming is so violent that competent individuals observing the shaking would recognize it as dangerous." 174 The 2001 AAP position paper doubled down on that claim, adding that the forces would be "so violent that individuals observing it would recognize it as dangerous and likely to kill the child." ${ }^{175}$ The forces could not have been accidental. The hypothesis and attendant testimony explicitly address mens rea. ${ }^{176}$

Such claims, it turns out, are entirely unscientific and indeed wrong. There simply is no scientific research establishing that the brain injuries in these cases require such extreme forces. When pushed, even prosecution experts who make such claims have to admit that there is no science underlying these claims. ${ }^{177}$ One need only pause and think about it for a moment to intuit the preposterousness of a claim that a single human being can manually generate forces equivalent to a thirty to sixty miles per hour unrestrained automobile crash or a multistory fall. And the biomechanical research confirms what intuition tells usboth that the most violent shaking cannot generate forces anywhere close to those described by the child abuse physicians, and that serious brain injuries can in fact be caused by much less obviously fatal forces,

172. Holmgren, supra note 44 , at 307.

173. See supra note 171 and accompanying text.

174. Am. Acad. of Pediatrics, Comm. on Child Abuse \& Neglect, Shaken Baby Syndrome: Inflicted Cerebral Trauma, 92 PedIATRICs 872, 872 (1993).

175. Am. Acad. of Pediatrics, Comm. on Child Abuse \& Neglect, supra note 171, at 206 (emphasis added).

176. Holmgren, supra note 44, at 307 (child abuse prosecutor urging that such testimony helps prove "the mens rea requirements for the charge").

177. For example, Dr. Jeffrey Jentzen, testifying for the prosecution in a Wisconsin courtroom, testified as follows:

Q. Now, there is really no scientific basis, however, for saying that's the amount of force it takes [e.g. the equivalent of a motor vehicle accident or multi-story fall], is there?

A. No. Other than the fact we see that type of injury and those kind of injuries.

Q. So sort of anecdotal, observational, cumulative kind of experience kind of thing?

A. Yes. Along with interview questionnaires with individuals who have been involved in those kind of events.

Transcript of Testimony of Dr. Jeffrey Jentzen at Evidentiary Hearing at 30, State v. Edmunds, No. 96-CF-555 (Dane Cty. Cir. Ct. Feb. 22, 2007). 
such as those from falls of just several feet. ${ }^{178}$ Regardless, the point remains that by making such (unscientific) claims, physicians are attempting to do nothing more than answer the actus reus and mens rea questions, questions that are beyond their role as physicians bringing specialized scientific knowledge to bear on issues within the scope of their special expertise.

Thus, it is far from "the false hyperbole of the courtroom and sensationalistic media" 179 to understand SBS/AHT as a "medical diagnosis of murder." It is, instead, an accurate understanding of the nature and import of the opinions rendered by child abuse pediatricians who claim they can divine what external forces were applied to a child by a human actor, with what state of mind, and when (leading to identifying the perpetrator). When proffered to "diagnose" "abuse," the medical expert's testimony often does indeed satisfy all of the elements of the case: what happened, who did it, and with what state of mind?

Moreover, it was not even lawyers in the courtroom, or the "sensationalistic media," that first likened SBS to a medical diagnosis of murder. It was, instead, a serious scholar and professor of law, Deborah Tuerkheimer, then at DePaul University College of Law, now at Northwestern University School of Law, herself once a child abuse prosecutor in New York, who dispassionately reviewed the medical and legal literature on the subject and first recognized that physicians were being called upon to decide legal questions in the guise of rendering medical opinions; it was she who labeled SBS a "medical diagnosis of murder." ${ }^{180}$ Thus, that likening did not originate in the "sensationalistic media," but in respected law journals ${ }^{181}$ and a book published by Oxford University Press. ${ }^{182}$ The media has indeed reported on the rupturing controversies in this field, but that media coverage has hardly been of the tabloid variety. The most hard-hitting coverage, and hence the coverage that prosecutors and child-abuse pediatricians typically rail against, has included extensive pieces in the New York Times, ${ }^{183}$ the

178. See, e.g., Duhaime et al., supra note 31; Prange et al., supra note 31; Ommaya et al., supra note 33, at 226; Werner Goldsmith \& John Plunkett, $A$ Biomechanical Analysis of the Causes of Traumatic Brain Injury in Infants and Children, 25 Am. J. Forensic Med. \& PATHOlOGY 89 (2004).

179. Choudhary, supra note 10 , at 1049.

180. See Tuerkheimer, supra note 163, at 5; Tuekheimer, supra note 169, at $515-16$.

181. See sources cited supra note 180 .

182. TUERKHEIMER, supra note 46.

183. Emily Bazelon, Shaken-Baby Syndrome Faces New Questions in Court, N.Y. TimeS (Feb. 2, 2011), https://www.nytimes.com/2011/02/06/magazine/06babyt.html?scp =1\&sq=emily\%20bazelon\%20shaken\&st =cse [https://perma.cc/J2X3M4KF]; Clyde Haberman, Shaken Baby Syndrome: A Diagnosis That Divides the Medical World, N.Y. TIMES (Sept. 13, 2015), 
Washington Post, ${ }^{184}$ the American Bar Association Journal, ${ }^{185}$ and National Public Radio and Pro Publica, ${ }^{186}$ among others. We leave it to the reader to decide for herself if this is the "sensationalistic media" to which the SPR refers.

Finally, although it should be obvious to even a casual reader by now, we note that the SPR's analogy to a physician's diagnosis that death was caused by poisoning is inapt. In the poisoning analogy, it is true that the physician only offers medical evidence about the subject's physical conditions and the chemicals found in the body that caused death. The physician says nothing about the conduct of any outside actor-she addresses neither the actus reus nor the mens rea of any third party, nor the identity of anyone as the poisoner. For it is absolutely true in that scenario that the poison could have been ingested accidentally or suicidally, as well as homicidally. And even if a third party gave the victim the poison, the physician tells us nothing about the state of mind of that third person. But the "diagnosis" of SBS or AHT does much more than that-it tells us everything we need to know not only about the medical conditions that led to death, but also that some third party inflicted deadly trauma, and did so with such force that it could not have been accidental, and at a time when the accused had to have been present. The poisoning scenario would be analogous to SBS/AHT only if the physician purported to diagnose not just poisoning, but "inflicted" poisoning or "abusive" poisoning, by a person who was with the deceased at the time of death. The poisoning analogy lays bare the logical flaw in the SPR argument; indeed, it makes clear how the SBS/AHT "diagnosis" is different, and involves legal rather than medical conclusions.

https://www.nytimes.com/2015/09/14/us/shaken-baby-syndrome-a-diagnosis-thatdivides-the-medical-world.html [https://perma.cc/9DDH-VSHP].

184. Debbie Cenziper, Shaken Science: A Disputed Diagnosis Imprisons Parents, WAsH. Post (March 20, 2015), https://www.washingtonpost.com/graphics/investigations/shaken-babysyndrome/?noredirect $=$ on (multi-part series).

185. Mark Hansen, Unsettling Science: Experts Are Still Debating Whether Shaken Baby Syndrome Exists, A.B.A.J., Dec. 2011, at 49-55.

186. Joseph Shapiro, Rethinking Shaken Baby Syndrome, NPR (June 29, 2011, 12:00 AM), https://www.npr.org/2011/06/29/137471992/rethinking-shaken-babysyndrome [https://perma.cc/EY4H-2BER]. 


\section{IMPLICATIONS OF THE CONTROVERSIES AND LEGAL NATURE OF THE SBS/AHT CONCLUSIONS}

\section{A. The Significance of the Legal Nature of the SBS/AHT Conclusion}

The dispute about whether SBS or AHT is a medical diagnosis or a legal determination is more than just a dispute about semantics or taxonomy. It matters for purposes of determining what the courts will do with such opinions. If it is a legal determination, courts cannot just defer to the physicians. Instead, courts must decide whether it is even permissible and appropriate for physicians to offer opinions about legal determinations that go beyond their medical training and expertise.

\section{The Limitations of MEDiCAl EXPERTISE In A LEGAL CONTEXT}

The law explicitly recognizes that determining whether a caregiver "has physically abused a child is a legal determination to be made by the factfinder" - that is, the judge or jury. ${ }^{187}$ The American Law Institute (ALI), in its newly adopted Restatement on Children and the Law, states, therefore, that the role of the expert witness is not to make such determinations, but is instead limited to "diagnos[ing] the child's medical conditions, including for example, broken bones, bruising, internal bleeding, and swelling, as well as the medical consequences of those conditions for the child." 188 The ALI defines the limits of the expert's authority in this way:

In addition to allowing a medical expert to render opinions regarding diagnoses of the child's bodily condition, a court may also allow a medical expert to render opinions regarding the external forces that may have caused the child's conditions. A medical expert may testify, for example, about whether a child's injuries are consistent with a parent's testimony that the child was injured while playing or whether the injuries are consistent with blunt force trauma inflicted by the parent. Determinations regarding the external forces that may have caused the child's condition exceed the scope of a diagnostic determination, however, and therefore the court must separately ascertain that the medical expert has

187. Restatement of ChildRen AND THE LAW $\S 3.20$ (AM. LAW Inst., Tentative Draft No. 1, Apr. 6, 2018).

188. Id. 
appropriate expertise to render an opinion on such issues and that the opinion is adequately grounded in science. ${ }^{189}$

Recently, a Michigan appellate court recognized this limitation in an SBS/AHT case. The court held:

Notwithstanding the propriety of a diagnosis of inflicted trauma, we conclude that in cases involving allegations of abuse, an expert goes too far when he or she diagnoses the injury as "abusive head trauma" or opines that the inflicted trauma amounted to child abuse. The ordinary understanding of the term "abuse"-as opposed to neglect or carelessnessimplies a level of willfulness and moral culpability that implicates the defendant's intent or knowledge when performing the act that caused the head trauma. An expert may not offer an opinion on the intent or criminal responsibility of the accused. ${ }^{190}$

Current practice among child-abuse physicians routinely runs afoul of this limitation, as does the SPR's attempt to claim diagnosing abuse as a purely medical determination.

The error can be understood by considering other forensic disciplines that have run into trouble because analysts have testified to statistical probabilities that lack a scientific foundation, or worse, to near or even absolute certainty about the match of crime scene evidence to a suspect-often in the guise of offering conclusions "to a reasonable degree of scientific certainty." In its 2009 report on forensic sciences,

189. Id. The Reporter's Comment elaborates:

In both criminal and civil child-protection proceedings, courts often allow medical experts to testify to their conclusion that physical abuse has occurred. See, e.g., People v. Weeks, 369 P.3d 699 (Col. App. 2015) (a medical expert may express a medical opinion that the child's injuries were caused by intentional child abuse "so long as (1) he or she does not give an opinion on whether or not the defendant inflicted the injuries or whether the injuries fit the legal definition of child abuse and (2) the jury is properly instructed that it may accept or reject the opinion."). This Section adopts a more constrained role for medical expert testimony, limiting it to the child's diagnoses, the effects of the diagnoses for the child, and, where reliable, the medical expert's opinion of the external forces believed responsible for the child's diagnoses. The conclusion that the child's diagnoses were the result of abuse is a decision that should be left solely to the trier of fact.

Id. (footnotes omitted).

190. People v. McFarlane, 926 N.W.2d 339, 350 (Mich. Ct. App. 2018). Despite this holding, the court in McFarlane also suggested that physicians may opine that a child's injuries were "inflicted." Id. This part of the decision makes little sense, however, because calling an injury "inflicted" is effectively equivalent to calling it "abusive." 
the National Academy of Sciences identified such scientifically baseless claims-claiming certainty or high statistical likelihoods when there was no basis for either-as a serious problem with forensic expertise in the courtroom. ${ }^{191}$

As a stark example of this type of error, in 2015, the FBI, working in collaboration with the Innocence Project and the National Association of Criminal Defense Lawyers, examined the testimony of its microscopic hair examiners in 268 cases from several decades prior to 2000 , finding that the analysts had testified in scientifically erroneous or unsupportable ways in ninety-five percent of those cases. ${ }^{192}$ The problem? Primarily, the analysts tended to make statistical or certainty claims that had no scientific basis, such as claiming that they had examined 10,000 hairs and had never found one like the one at issue, or even giving specific astronomical odds of error, when no research supported those statistics. ${ }^{193}$

Yet in child abuse cases, that is precisely the type of unscientific certainty or odds claim that physicians make routinely-and that the SPR so vehemently defends as a matter of medical diagnosis. But there simply is no basis for "diagnosing" abuse to the exclusion of all other causes of a child's condition based on brain and eye findings, with or without other medical findings. Dr. Kent Hymel and a team of leading AHT/SBS proponents have acknowledged that "[g]old standard definitional criteria for AHT do not exist." 194 They add that "in the absence of a gold standard, clinicians can rarely confirm or exclude AHT with complete certainty and are compelled instead to adopt a probabilistic approach to the diagnosis." ${ }^{195}$ All knowledgeable child abuse physicians today agree that there is no established diagnostic standard, and that the diagnosis is made upon the basis of a variety of findings, each of which may or may not be present in any given case. ${ }^{196}$ In the end, they contend, it comes down to clinical judgment. ${ }^{197}$ It

191. National Academy of Sciences, Strengthening Forensic Science in THE UNited STATES: A PATH ForWARD 47, 184, 186 (2009).

192. Spencer S. Hsu, FBI Admits Flaws in Hair Analysis over Decades, WASH. Post (April 18, 2018), https://www.washingtonpost.com/local/crime/fbioverstated-forensic-hair-matches-in-nearly-all-criminal-trials-fordecades/2015/04/18/39c8d8c6-e515-11e4-b510$962 \mathrm{fcfabc310}$ story.html?noredirect $=$ on\&utm term $=.47 \mathrm{a} 948574 \mathrm{~cd} 9$.

193. Spencer S. Hsu, Convicted Defendants Left Uninformed of Forensic Flaws Found by Justice Dept., WASH. PosT (April 16, 2012), https://www.washingtonpost.com/local/crime/convicted-defendants-left-uninformed-offorensic-flaws-found-by-justice-dept/2012/04/16/gIQAWTcgMT_story.html.

194. Kent P. Hymel et al., Derivation of a Clinical Prediction Rule for Pediatric Abusive Head Trauma, 14 Pediatric Critical Care Med. 210, 212 (2013).

195. Id. at 217.

196. See id. at 212.

197. See, e.g., Narang, supra note 49, at 529. 
should be apparent, however, that any exercise of clinical judgment is susceptible to error, even in contexts where there are clear and welldefined diagnostic criteria (indeed medical misdiagnosis is a serious problem in all areas of medicine). ${ }^{198}$ But the typical testimony offered by a child abuse physician is to assert a diagnosis "to a reasonable degree of medical certainty," without acknowledging any likelihood of an alternative or any probability of misdiagnosis. Child abuse physicians routinely claim that all other possibilities have been ruled out, or that nothing else but shaking or shaking with impact could have caused the child's condition, or that a short fall could not have caused the injuries, or that a lucid interval was not possible, or the like. ${ }^{199}$ The SPR takes this all a step further, contending that such claims are noncontroversial, and that defense critics who point out the uncertainties and the alternative possibilities have no place in the legal proceedings in which abuse is alleged. ${ }^{200}$

Indeed, one of the nation's most visible and outspoken SBS/AHT prosecutors, Brian Holmgren, has urged that in SBS/AHT cases the ethical expert should claim definiteness even when the medical evidence in the expert's opinion merely makes abuse very likely. ${ }^{201}$ Holmgren acknowledges, for example, that accidental short falls can sometimesalbeit rarely-produce the same constellation of signs and injuries (or death) that are used to diagnose SBS/AHT. Nonetheless, he argues that,

198. Medical experts recognize that, across all types of medical diagnoses, "[c]ases of delayed, missed, and incorrect diagnoses are common, with an incidence in the range of [ten to twenty percent]," and error is higher in clinical diagnoses and lower with respect to diagnostic tests. Mark L. Graber et al., Bringing Diagnosis into the Quality and Safety Equations, 308 J. AM. MED. Ass'N 1211, 1211 (2012); “[I]t is clear that an extensive and ever-growing literature confirms that diagnostic errors exist at nontrivial and sometimes alarming rates. These studies span every specialty and virtually every dimension of both inpatient and outpatient care.” Eta S. Berner \& Mark L. Graber, Overconfidence as a Cause of Diagnostic Error in Medicine, 121 AM. J. MED. S2, S6 (2008).

Moreover, these errors are not just failures to recognize and diagnose diseases or conditions; the errors are often those of over-diagnosis. In another pediatric realm, for example, pediatricians misdiagnose ear infections an average of fifty percent of the time, and most of the errors are of over-diagnosis (Type 1 errors) and over-prescription of antibiotics. Michael E. Pichichero \& Michael D. Poole, Assessing Diagnostic Accuracy and Tympanocentesis Skills in the Management of Otitis Media, 155 Archives Pediatric Adolescent Med. 1137, 1137, 1139 (2001); Richard M. Rosenfeld, Diagnostic Certainty for Acute Otitis Media, 64 InT'L J. PediATRIC Otorhinolaryngology 89, 89 (2002); Michael E. Pichichero \& Michael D. Poole, Comparison of Performance by Otolaryngologists, Pediatricians, and General Practitioners on an Otoendoscopic Diagnostic Video Examination, 69 INT'L J. PEDIATRIC OTORHINOLARYNGOLOGY 361, 361, 365 (2005).

199. Findley et al., supra note 3, at 214.

200. Choudhary et al., supra note 10, at 1049.

201. Brian K. Holmgren, Ethical Issues in Forensic Testimony Involving Abusive Head Trauma, 3 ACAD. Forensic Pathology 317, 319 (2013). 
"if the question [to the expert] is phrased 'to a reasonable degree of medical certainty, [did] a short fall . . . cause the death of this child?' . . . then the correct answer should be 'no' given the extreme unlikelihood of such an event." 202

But of course, the answer should not be "no." The answer should be, "I cannot say with certainty based upon the medical evidence available to me. Short falls can cause such medical signs and injuries (or death), but it is rare. Nothing in the medical research or my findings in this case permits me to say that this case is not one of those rare ones." And if a caregiver or witness provides a history of a short fall, the answer should be, "Nothing in the medical research or my findings in this case permits me to say that this history is false, or that this short fall could not be the cause of this child's condition," or "the medical evidence in this case is consistent with the fall described by the caregiver." As the American Medical Association has cautioned, "it is ethically important for a physician expert witness to make clear . . . that probabilities not be misrepresented as definitive conclusions." 203

The SPR, like Holmgren, seeks to claim an authoritativeness and certainty that the science does not permit, at least not in a legal context.

\section{ADMISSIBILITY ISSUES ARISING FROM THE LEGAL NATURE OF THE "DIAGNOSIS"}

All of this means, of course, that not everything the SPR seems to claim to be within the expertise of the "diagnosing" physician is admissible under the Rules of Evidence. Whether a jurisdiction follows Frye's "general acceptance" standard or Daubert's "reliable science" standard, limitations, not recognized by the SPR, will apply.

First, because claims of definitiveness or specific odds-based claims are scientifically unsupportable, under Daubert they exceed the scope of permissible testimony. Likewise, under Frye, because all knowledgeable physicians recognize that "diagnosing" abuse involves clinical judgment, and is not testable by any definitive test, any claim to definitiveness of the "diagnosis" cannot be said to achieve "general acceptance" in the medical community.

Certainly, physicians can identify observed medical conditions, such as subdural or subarachnoid hematomas, retinal hemorrhages, cerebral edema, fractures, or the like. And as the ALI observes, if there is a reliable basis in the research physicians may testify about whether, in the physician's opinion, such findings are consistent with various possibilities presented, including "whether the injuries are

202. Id. (emphasis in original).

203. Michael S. Goldrich, American Medical Association, Report of the Council on Ethical and Judicial Affairs (CEJA Report 12 - A-04), at 3 (2004). 
consistent with blunt force trauma inflicted by the parent." 204 But the physician may not rule out innocent causes simply because they are rare, or because the mechanism of injury is not well understood. And the physician may not opine about what particular actions a third-party took to cause those injuries, or whether any trauma was inflicted knowingly or intentionally rather than accidentally. In other words, the physician may not "diagnose" abuse in the courtroom.

To be sure, to date most courts, without a lot of thought or analysis, have admitted SBS/AHT expert testimony (for both sides) without limitation (in this regard, the courts have not improved on their utter failure to regulate adequately the admissibility of almost all other unscientific and unreliable forensic evidence in criminal cases). ${ }^{205} \mathrm{But}$ the medical research challenging many aspects of the SBS/AHT hypothesis is growing, the ALI statement is new, and defense lawyers and courts are just now beginning to become sophisticated enough in this complicated area of medicine and law to understand the appropriate limitations that should apply. The opportunities for getting it right are, in short, growing.

A very recent decision from a court in Florida further illustrates one way that a more thoughtful admissibility inquiry might play out. In State v. Kent Johnson, ${ }^{206}$ after an evidentiary hearing on the admissibility of the state's experts' SBS/AHT testimony, the court excluded those parts of the experts' proposed testimony that would have gone beyond medical diagnosis of the child's medical conditions and wandered into much less well-grounded medical hypotheses that intrude on legal judgments. ${ }^{207}$ The court ruled:

The Court finds that the term "Shaken Baby Syndrome" and related terms set forth above [including also "shaking,"

204. Restatement of ChildRen AND THE LAW $\S 3.20$ (AM. LAW Inst., Tentative Draft No. 1, 2018).

205. See, e.g., Margaret A. Berger, Expert Testimony in Criminal Proceedings: Questions Daubert Does Not Answer, 33 Seton Hall L. REV. 1125, 1125 (2003); Peter J. Neufeld, The (Near) Irrelevance of Daubert to Criminal Justice and Some Suggestions for Reform, 95 Am. J. Pub. Health S107 (2005); D. Michael Risinger, Navigating Expert Reliability: Are Criminal Standards of Certainty Being Left on the Dock?, 64 ALB. L. REV. 99, 143-49 (2000); Jennifer L. Groscup et al., The Effects of Daubert on the Admissibility of Expert Testimony in State and Federal Criminal Cases, 8 Psychol. Pub. PoL'y \& L. 339, 342 (2002); Randolph N. Jonakait, The Meaning of Daubert and What That Means for Forensic Science, 15 CARDOZO L. REV. 2103, 2117 (1994).

206. Order Granting Defendant's Amended Motion In Limine to Exclude Any Testimony Regarding Shaken Baby Syndrome or in the Alternative Request for a Frye Hearing, State v. Johnson, Case No. 15-CF-018630-A, (Fla. Hillsborough Ct., Oct. 17, 2018).

207. Id. at $1-2$. 


\begin{abstract}
"shaken baby," "rotation acceleration," or "accelerationdeceleration force"] to be supported by insufficient scientific data and evidence. The Court finds that after reviewing the motion, argument, and testimony from various witnesses, there is ample evidence to demonstrate that the terminology does not adequately describe the range of potential causes of head injuries. There is no established science to support "Shaken Baby Syndrome" as a valid diagnosis. Thus, Defendant's motion is granted and the Court limits the use of the phrase "Shaken Baby Syndrome" and related phrases stated in this Order from being used in the course of Defendant's trial. ${ }^{208}$
\end{abstract}

It is too early yet to know if this decision will be appealed and, if so, whether it will stand up on appeal, or whether it will be followed by other courts. But it does at least reflect growing recognition of the legal problems with expert testimony in this field.

Regardless, even if broadly framed admissibility challenges like this prove unavailing in other cases, at the very least some aspects of the traditional SBS/AHT dogma are now so thoroughly undermined that testimonial assertions related to them should not survive Daubert or Frye challenges. Those include assertions that at one time were ubiquitous, but now have been shown to be scientifically wrong or void of any scientific foundation, including assertions such as (but not limited to):

- Short falls cannot kill or cause serious brain injury (including the triad and related findings);

- The forces required to cause such injuries would have to be so massive as to be recognizable to any observer as likely to kill or seriously harm the child, equivalent to the forces in a high-speed automobile crash or a multi-story fall;

- Nothing could cause the various medical findings relied upon to "diagnose" abuse except shaking, shaking with impact, or inflicted blunt force trauma;

- Lucid intervals between the time of injury and collapse are not possible in cases involving serious brain injury.

208. Id. See also Clark v. State, No. 2017-KA-00411-COA, 2019 WL 5566234, ๆ 47-48 (detailing how a Mississippi appellate court decision issued just as this article was going to press holding that testimony "diagnosing" SBS was unreliable and "should therefore have been excluded," because "[t]here was no proof that the medical science ... reliably explained the biomechanical processes by which SBS or AHT develop. ... . [and because t] here was . . . no proof that the medical science ... reliably aided the jury in understanding the cause and timing of [the child's] death."). 


\section{B. Legal Implications of the Controversy}

That the SBS/AHT "diagnosis" is controversial also has legal implications. In part, the controversy adds to the admissibility questions under Daubert or Frye discussed above. To the extent that both Daubert and Frye turn at least in part on "general acceptance," the fact that so many propositions involved in diagnosing SBS/AHT in any given case are controversial means that the controversies raise doubts about admissibility.

The controversy also has legal implications for the duties of defense counsel in representing individuals accused of child abuse. Because so many of the propositions underlying the SBS/AHT "diagnosis" in any given case are scientifically debatable, courts are increasingly recognizing that defense counsel fail to meet Sixth Amendment standards for effective assistance of counsel if they fail to obtain expert assistance from appropriate medical and/or other scientific experts, including from those who are critical of the hypothesis. ${ }^{209}$

Similarly, the disputes impose obligations on trial courts to ensure that indigent defendants have the funds necessary to hire appropriate

209. See, e.g., West Virginia Innocence Project Client Freed from Prison, WVUTODAY (Aug. 16, 2018), https://wvutoday.wvu.edu/stories/2018/08/16/westvirginia-innocence-project-client-freed-from-prison [https://perma.cc/TU8J-USUW]; Order Granting Post-Conviction Relief, Reversing Petitioner's Judgment and Sentence, and Remanding to the District Court of Wagoner County for a New Trial, Brafford $v$. State, No. PC-2014-803 (Okla. Crim. App., Mar. 26, 2019) (on file with author); Maurice Possley, Krystal Voss, NAT'L REgistry of Exonerations (Sept. 20, 2017), http://www.law.umich.edu/special/exoneration/Pages/casedetail .aspx? caseid $=5198$ [https://perma.cc/5SEA-BQ37]; Commonwealth v. Millien, 50 N.E.3d 808, 814, 81618 (Mass. 2016); Commonwealth v. Epps, 53 N.E.3d 1247, 1255, 1258, 1263 (Mass. 2016); People v. DiMambro, 897 N.W.2d 233 (Mich. Ct. App. 2016); People v. Ackley, 870 N.W.2d 858, 867 (Mich. 2015); State v. Pheils, No. WD-14-072, 2015 WL 5306548 (Ohio Ct. App. 2015); Sissoko v. State, 182 A.3d 874, 876 (Md. Ct. Spec. App. 2018) (noting that initial conviction was overturned based on ineffective assistance of counsel, and then affirming conviction after retrial); Memorandum, Statement of Reasons, and Order Regarding Petition for Post-Conviction Relief, Dobson v. State, No. 20-K-09-9572 (Cir. Ct. Kent Cty., Apr. 7, 2014); Adam Armour, Judge Vacates Convicted Murderer's Guilty Plea, Itawamba CTY. Times (July 2, 2014), https://www.djournal.com/itawamba/news/itawamba-county/judge-vacatesconvicted-murderer-s-guilty-plea/article_dea69b1f-bbd7-5d73-bd14-236634add1d7.html [https://perma.cc/Z48S-WPT6]; Joseph Shapiro, Judge Tosses Conviction of Texas Man Accused of Sexually Assaulting Infant, NPR (Jan. 26, 2012, 11:29 AM), https://www.npr.org/blogs/thetwo-way/2012/01/26/145901310/judge-tosses-convictionof-texas-man-accused-of-sexually-assaulting-infant [https://perma.cc/D8RN-DMD2]; Armando Castillo, AZ Just. Project (May 21, 2015), https://www.azjusticeproject.org/manifest-injustice-profiles/armando-castillo [https://perma.cc/45EG-3223]; State v. Schoonmaker, 176 P.3d 1105, 1116 (N.M. 2008); State v. Hales, 152 P.3d 321 (Utah 2007); Ex Parte Briggs, 187 S.W.3d 458 , 469 (Tex. Crim. App. 2005). 
experts to assist them in these medical-science-dependent prosecutions. In this regard, courts are also recognizing that failure to appoint the necessary defense experts in these cases violates due process under the principles enunciated in Ake v. Oklahoma. ${ }^{210}$

Finally, the controversy has implications for courts assessing postconviction challenges to prior SBS/AHT convictions based on claims of newly discovered evidence. As noted above, when a conviction is obtained on the basis of uncontroverted medical opinion evidence presenting SBS/AHT as settled science with no alternatives, the new research raising the various challenges that create the serious controversies today can be and is increasingly being used as the basis for granting a new trial based on newly discovered evidence. ${ }^{211}$ As numerous courts have now recognized, when a case is presented as based on settled science, and especially when that settled science constitutes the bulk of the prosecution's case, new evidence that the science is not so certain requires a new trial at which a jury can fully consider the competing claims. ${ }^{212}$

\section{CONCLUSION}

In its "consensus statement," the SPR tries to wave away the roiling controversy about the reliability of SBS/AHT "diagnoses" by declaring that there is, in fact, no genuine controversy and that, in any event, the question is purely one of medical diagnostics for which courts should defer to medical judgments. We have shown that SPR is wrong on both counts. There are very serious questions about the reliability of SBS/AHT "diagnoses," and those questions cannot be papered over by bringing together a guild of true believers to publish a "consensus statement." And the SBS/AHT "diagnosis" is inherently a legal judgment for which the courts must continue to play a gatekeeping role.

210. Ake v. Oklahoma, 470 U.S. 68, 76 (1985). For examples of cases reversing SBS/AHT convictions based on Ake violations, see Isham v. State, 161 So.3d 1076 (Miss. 2015); Brown v. State, 152 So. 3d 1146, 1170 (Miss. 2014); State v. Gallaway, 2015 WL 4460992 (Del. 2015); McDonald v. State, 101 So.3d 914, 916 (Fla. App. 2012).

211. See cases cited supra note 209.

212. For a fuller discussion of these issues, see Findley \& Risinger, supra note 64 , at $1224-25$. 


\section{APPENDIX 1}

October 27, 2017

Via Email and Regular U.S. Mail

Society for Pediatric Radiology

1891 Preston White Drive

Reston, VA 20191

Re: "Consensus Statement on Abusive Head Trauma in Infants and Young Children"

We are longstanding SPR members who have published, lectured and consulted on shaken baby syndrome/abusive head trauma (SBS/AHT) and related subjects. On October 17 we received via email a lengthy (50 page, 211 reference) paper titled Consensus Statement on Abusive Head Trauma in Infants and Young Children whose stated purpose is to provide guidance to the courts, the media and the public. While the SPR's Child Abuse Imaging Committee led the effort to prepare the Statement, the authors include several child abuse pediatricians and a law professor who are leading advocates of the SBS/AHT hypothesis. The email invites comments, but imposed a deadline of October 27. This was the first we had heard about any of this.

Because of the short timeframe for comment, which is limited to SPR members, our feedback is abbreviated. We provide these preliminary comments to meet the October 27 deadline, but ask for an opportunity to submit a more complete response. Should the SPR publish the Consensus Statement, we ask that the response be published with the Statement or shortly thereafter. We also recommend that comments be invited from other interested parties.

Our concern is that as presently written, the Statement is likely to be misleading to the courts and others on the nature and extent of the SBS/AHT controversy. SBS/AHT refers to the hypothesis that shaking or abuse may be reliably inferred from various internal radiological or pathological findings, none of which are specific to trauma. The Consensus Statement characterizes the literature supporting the SBS/AHT hypothesis as based on medical science and the literature questioning the reliability of the inference or suggesting alternative causes as grounded in denialism of child abuse and a desire to improve defense outcomes for abusive caretakers. This is incorrect. We are familiar with the medical, scientific and legal literature that raises concerns about the quality of evidence supporting SBS/AHT beliefs and there is no denialism of child abuse within that literature. There is, however, considerable and growing concern about the reliability of the diagnostic criteria and an increasing interest in the differential diagnosis for the findings on which the diagnosis is based.

\section{The Controversy}


The Consensus Statement suggests that there is no legitimate controversy on SBS/AHT. In recent years many courts have acknowledged the existence of a legitimate controversy on this subject. The controversy also exists within the medical, scientific and legal literature. In 2016, a report from the President's Council of Advisors on Science and Technology on the scientific flaws in numerous areas of forensic science stated that SBS/AHT was a subject beyond the scope of the report, but is a matter that requires "urgent attention." In October 2016, a Swedish governmental agency published the results of a two year review of the evidence base for SBS that concluded that the traditional diagnostic criteria for SBS were unreliable and based on low or very low quality evidence, with the only support coming from two confession articles. Views that the Consensus Statement holds out as matters of general acceptance are also widely questioned in the fields of forensic pathology and biomechanics.

\section{The Diagnostic Criteria}

The Consensus Statement states that SBS/AHT is a "medical diagnosis" but does not mention that the diagnostic criteria have changed substantially over the past decades. Instead, the Statement seeks to inform judges, jurors, the media, and the public that the critiques of SBS/AHT proceed from the "deliberate mischaracterization" that SBS/AHT is diagnosed based on a "triad" of findings rather than a multidisciplinary medical and nonmedical investigation. However, the triad findings (subdural hemorrhage, retinal hemorrhage and cerebral edema and/or encephalopathy) have had and continue to have enormous significance in diagnosing SBS/AHT. The child abuse literature is filled with references to the triad, or merely the presence of subdural and retinal hemorrhage in the absence of a history of major trauma, as being virtually diagnostic of SBS/AHT. It is therefore critical to evaluate the diagnostic value of these elements, individually and in combination, as well as to understand the range of alternative traumatic and non-traumatic conditions that result in these findings. When one does so, major

concerns emerge.

\section{The Pathological Assumptions}

The SBS hypothesis stemmed from assumptions that the cerebral edema, subdural hemorrhage, and retinal hemorrhages found in children without external evidence of significant head trauma reflected traumatic diffuse axonal injury, ruptured bridging veins, and vitreoretinal hemorrhage, and that in nearly all instances repetitive violent shaking best explained these "shearing injuries." We now know, however, that the cerebral edema typically reflects hypoxicischemic injury rather than DAI; that the scant or thin subdural hemorrhage common in these cases may reflect oozing from within the dura rather than torn bridging veins; and that retinal hemorrhages occur 
in a wide range of traumatic and non-traumatic conditions. There is as yet no evidence to validate vitreoretinal traction as the source of retinal findings in children. Accordingly, viewing these findings as indicative of shaking is an increasingly dubious hypothesis. Any Consensus Statement should acknowledge the overlap in findings between accidental injuries, abusive injuries and natural causes.

\section{Short Falls}

A common history in children presenting with subdural hemorrhage, retinal hemorrhage, and/or seizures or other neurologic defect is that the children sustained a short fall or similar accidental trauma. For years the prevailing guidance in the child abuse literature was that this history was necessarily false. The current evidence, which includes at least two videotaped and many witnessed short falls, now provides indisputable evidence that short falls in young children may cause all of these findings and, occasionally, death. Several court decisions have recognized the evolving understandings in this area. The prevailing view in forensic pathology is that a history of a short fall in the presence of an isolated impact injury cannot be rejected as a potential explanation for subdural hemorrhage, retinal hemorrhage, brain injury or even death.

\section{The Quality of the SBS/AHT Evidence Base}

The reliability of SBS/AHT diagnoses depends on the quality of the evidence that has historically reported strong associations between the triad findings and SBS/AHT. It is now recognized that the SBS/AHT literature is based largely on studies that used circular and self-fulfilling methodology-e.g., subdural and retinal hemorrhages were used as primary diagnostic and classification criteria for SBS/AHT in studies that then reported an extremely high rate of such hemorrhages in SBS/AHT. This circular reasoning has been noted in meta-analyses, and a leading 2011 child abuse textbook further concluded that confessions were the evidence base for SBS. The recent Swedish Report similarly found that nearly the entire SBS evidence base is circular and unreliable. The two papers it classified as moderate quality were confession papers. The Consensus Statement ignores these evidentiary concerns and dismisses the Swedish Report in a few sentences, citing comments accusing its authors of unethical bias and of unreasonableness in refusing to accept the findings of child protection teams as sufficiently reliable for study classification purposes. The Statement does not refer to an additional paper published by the authors of the Swedish Report titled Is Accepting Circular Reasoning in Shaken Baby Studies Bad Science or Misconduct?, in which the authors explained that using "the classification used by child protection teams as the gold standard for classifying study cases and controls entails a high risk of bias and carries a risk that false positive cases are presented as true-positive cases." The citation of responses to the Report, 
including by one of the Statement's authors, while omitting replies from the Report's authors is inappropriate for a "Consensus Statement."

\section{Natural Causes}

As faith in the diagnostic specificity of the triad has waned, attention has turned to alternative explanations for the findings previously viewed as diagnostic or even pathognomonic of shaking. Many controversies and unknowns exist concerning the diagnostic criteria for alternative diagnoses; many of them are rare, have been incompletely studied, and/or have been underdiagnosed because of mistaken beliefs that the triad findings reflected SBS/AHT. The guidance offered by the Consensus Statement on a handful of natural causes that produce similar findings is misleading. We offer immediate feedback about the Statement's criticisms of two of these diagnoses.

Cerebral Venous Thrombosis (CVT). The Consensus Statement asserts that CVT is not associated with subdural hemorrhage and, further, that findings attributed to CVT actually reflect intracranial venous injury caused by abuse. Outside the child abuse literature there is existing and growing awareness that CVT often produces intracranial hemorrhage, that it is rarely associated with trauma, and that it may be difficult on imaging to distinguish between thrombosed veins and extraaxial hemorrhage. While venous thrombosis may also occur in head injury, there is a general understanding that CVT has been underdiagnosed in the pediatric population and reason to believe that it has been misdiagnosed as SBS/AHT in the courtroom.

$B E S S$. Benign enlargement (or expansion) of the subarachnoid spaces ("BESS") is a diagnosis known by several names. The Consensus Statement advises that BESS was "initially thought to predispose to SDH with minimal trauma," but that recent reviews reveal that less than $6 \%$ of such patients develop subdural collections. The Statement urges caution about studies indicating a higher prevalence because they may have lacked adequate assessment for abuse. This guidance is not, however, a consensus position. A 2011 review summarized: "Several studies have shown an increased risk of subdural hematomas in children with external hydrocephalus after minimal or no known head trauma." The recent studies the Statement claims are more reliable should be examined to ensure that this is not a function of selection bias or circularity-e.g., the exclusion of cases diagnosed as SBS/AHT on the basis of the child having subdural or retinal hemorrhage, seizures, or a history of minor trauma.

$* * *$

As a matter of scientific vigor, continuing review of the strength of the evidence base for the SBS/AHT diagnosis is mandatory. In less than two decades we have seen a shift from dogmatic medical claims that the triad is diagnostic or even pathognomonic of shaking to the claim set forth in the proposed Consensus Statement that the triad is a "legal 
argument and not a medically valid term." As the discussion continues, we must remember that these are not abstract concepts but rather are diagnoses that are used to remove children from their homes and to imprison their parents and caretakers. In this context, attempting to demean or mischaracterize countering viewpoints reflects advocacy, not science. Should the SPR still intend to issue the Consensus Statement, we ask for the opportunity to publish a fuller response. We believe such a response can be completed within 30 days.

Sincerely,

Patrick D. Barnes, M.D.

Julie A. Mack, M.D. 